\section{Arkivoc}

Archive for

Organic Chemistry
The Free Internet Journal

for Organic Chemistry
Paper

Arkivoc 2018, part iii, 0-0

\title{
NMR solution structures and MD-simulation of procyanidin B1, B2, and C1
}

\author{
Amelia Watson, ${ }^{a}$ Christopher Wallis, ${ }^{b}$ and Andreas H. Franz ${ }^{a, *}$ \\ ${ }^{a}$ Department of Chemistry, University of the Pacific, 3601 Pacific Avenue, Stockton, CA 95 211, USA \\ ${ }^{b}$ Crop Diseases, Pests, and Genetics Research Unit, USDA-ARS San Joaquin Valley Agricultural Sciences Center, \\ 9611 S. Riverbend Ave, Parlier, CA 93 648, USA \\ E-mail: afranz@pacific.edu
}

Received 09-25-2017

Accepted 02-26-2018

Published on line 05-18-2018

\section{Abstract}

We describe the solution geometries of procyanidins $\mathrm{B} 1, \mathrm{~B} 2$, and $\mathrm{C} 1$ in methanol at low temperature by NMR spectroscopy, MD simulations with AMBER14/GAFF, and $a b$ initio structure calculations. The conformational space of all compounds was adequately sampled by the MD trajectories. The $a b$ initio calculations quantitatively matched the experimental data very well, both by experimental abundance in solution (Boltzmann statistics) and nOe-experiments. In contrast to literature reports, no evidence for significant $(M) /(P)$-rotation about the interflavanol linkages was found in either the experimental or computational data. Instead, conformational changes were limited to half-chair conformers or hydrogen-bonded rotamer subpopulations in the $(M)$-atropisomer space.
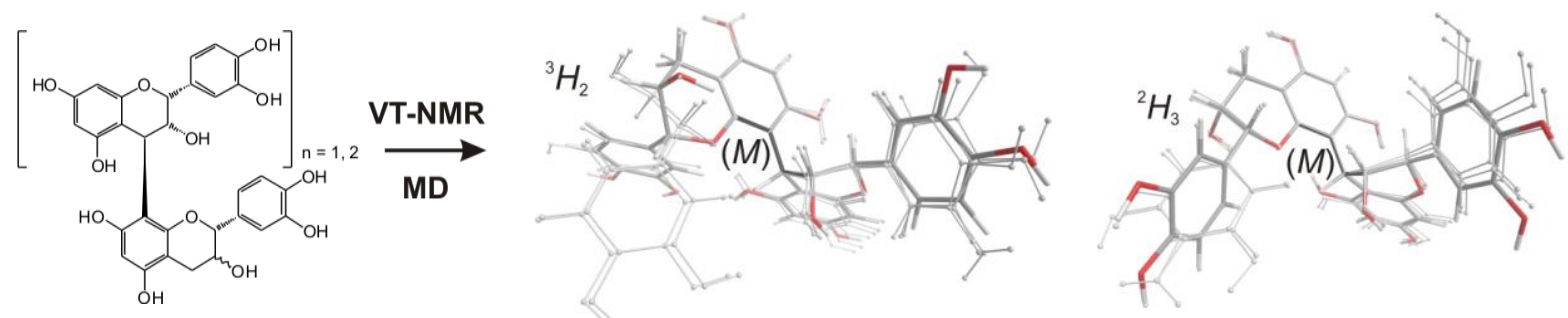

Keywords: Polyphenols, VT-NMR, coupling constant, atropisomer, conformation, AMBER molecular dynamics 


\section{Introduction}

Polyphenolic secondary metabolites play key roles in the biochemistry of plants and are divided into several different classes of compounds. Phenolic acids, coumarins, tannins, chalcones, aurones, flavanones, flavones, isoflavones, flavanols, proanthocyanidins, and anthocyanins are present abundantly in plants and can be isolated by extractions, capillary electrophoresis, and chromatography such as ion exchange, supercritical fluid, reverse-phase HPLC, and regular-phase HPLC. Soon after their discovery and even long before their detailed structural description, polyphenols were known for important medical benefits in traditional folk medicine. ${ }^{1,2}$ The structures of polyphenols were elucidated over time by mass spectrometry, ${ }^{3}$ and numerous spectroscopic techniques including Nuclear Magnetic Resonance (NMR). ${ }^{3}$ Along with detailed structure description, a more thorough understanding of the multitude of biochemical roles evolved. Hundreds of polyphenolic structures have been reported to date. The great structural diversity of polyphenols in plants complicates the isolation of sufficient material of a single specific compound for biochemical studies. Specific synthesis of polyphenols in the laboratory can be accomplished by total synthesis, ${ }^{4}$ by semi-synthetic modifications of natural polyphenols, ${ }^{4}$ and by metabolic engineering of microorganisms. ${ }^{5}$

Polyphenols of the flavanol category are composed of catechin or epicatechin with a plethora of chemical modifications. One characteristic structural feature of flavanols, and flavan-3-ols in particular, is that oxidative combination via C-C- or C-O-linkages results in different constitutional and diastereomeric oligomers. The C-Clinked isomers of flavan-3-ols are referred to as procyanidins (Fig. 1). The structural identities and stereochemistries of the procyanidins, have been established 40 years ago ${ }^{6-8}$ and their biochemical synthesis was elucidated soon after. ${ }^{9,10}$ Oligomerization of catechin or epicatechin units results in two conformational and stereochemical peculiarities. First, the direct C-C-linkage between two chiral flavanols is hindered in its rotational freedom, which leads to diastereomers because of atropisomerism. Second, the increased steric crowding in catechin/epicatechin oligomers can have a secondary conformational effect on the half-chair conformations of each catechin/epicatechin unit, which can exist in either ${ }^{2} \mathrm{H}_{3}$ or ${ }^{3} \mathrm{H}_{2}$-conformation. Several crystal structure studies have been published, ${ }^{11-16}$ namely one paper with the single crystal structure of epicatechin (1b) $\left({ }^{2} H_{3}\right),{ }^{11}$ one paper with both, the 3 -epimer 1 a, catechin, $\left({ }^{2} H_{3}\right)$ and catechin-3-gallate $\left({ }^{2} H_{3}\right),{ }^{14}$ and one paper with epicatechin-3-gallate-caffeine complex $\left({ }^{2} \mathrm{H}_{3}\right) .{ }^{16}$ Two papers have been published with protein structures that carry compound $\mathbf{1 b}$ as ligand in the ${ }^{3} \mathrm{H}_{2}$-conformation (PDB: 4MA6) in one case and 1a3-gallate in the ${ }^{3} \mathrm{H}_{2}$-conformation (PDB: 3QMU, glutamate dehydrogenase) in the other case. ${ }^{13,17}$ Interestingly, the conformation of $\mathbf{1 b}$ in the single-crystal structure was the same as in solution whereas the protein-bound structures displayed the opposite half-chair conformations. From these results of other groups, it has to be concluded that favorable interaction through hydrogen-bonding and van-der-Waals forces inside the protein's binding pocket apparently offset the Gibbs free energy expense in solution to adopt the opposite half-chair conformation, offset the desolvation enthalpy, and offset the loss in ligand entropy upon binding. To the best of our knowledge no single crystal structure has been reported for native procyanidin B1 (2), B2 (3), or C1 (4). However, one paper reports the structure of the peracetylated derivative of $\mathbf{2} .{ }^{15}$

Nevertheless, prior to the elucidation of the biochemical function of any polyphenol, unambiguous chemical structure elucidation in aqueous solution is essential. In solution, the structures of procyanidins are potentially complicated by significant conformational freedom or restricted by hydrogen bonding. The stereogenic structures of procyanidins affect plane- or circularly-polarized light, and the application of CD spectroscopy to the structure analysis of flavan-3-ols in solution has been reviewed. ${ }^{18,19}$ 


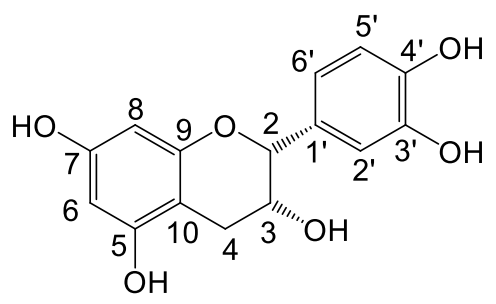

(-)-Epicatechin (1)

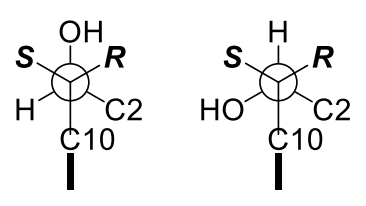

Definition of pro- $R$ and pro-S protons on $\mathrm{C} 4$

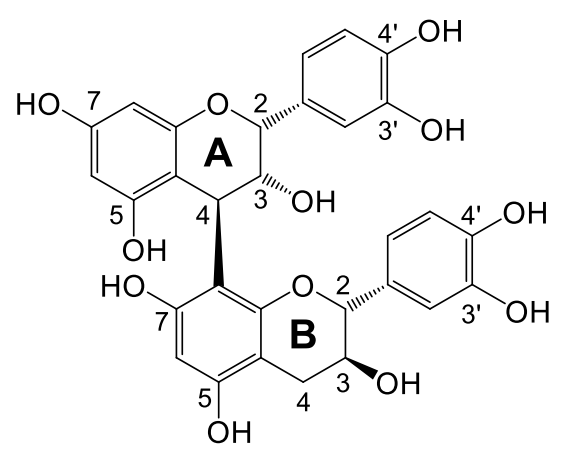

Procyanidin B1 (2)

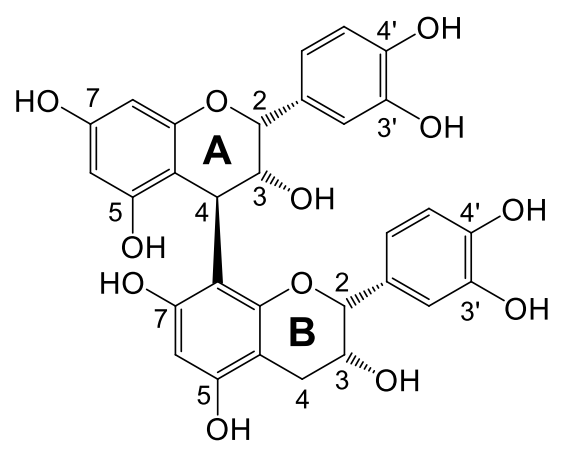

Procyanidin B2 (3)

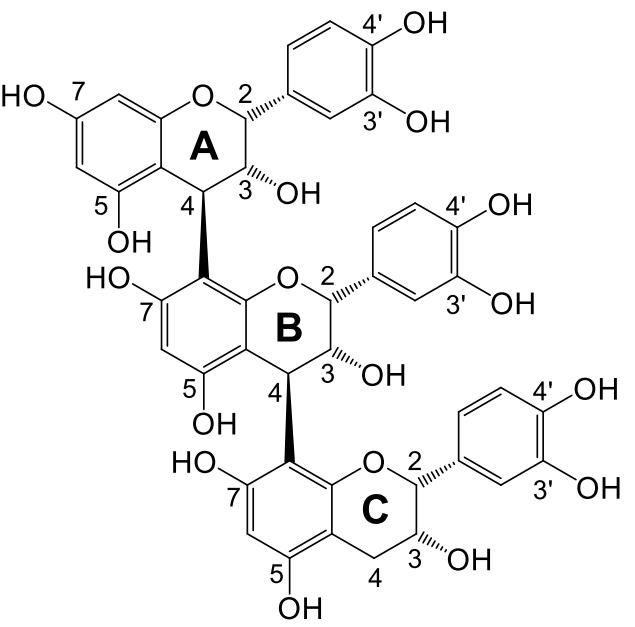

Procyanidin C1 (4)

Figure 1. Chemical structures of (+)-catechin (1a), (-)-epicatechin (1b), procyanidin B1 (2), B2 (3), and C1 (4).

In addition, NMR spectroscopy is particularly powerful to determine the structure of molecules in solution. Not only can atom connectivities be established (molecular constitution), but also stereochemical information (configuration) and three-dimensional geometry (conformation). Low-temperature NMR has allowed observing individual molecular conformations that might slowly interconvert at room temperature and which result in broad spectral peaks devoid of fine structure. The historical observation that narrow-line NMR spectra exhibited spectral "fine structure" and hence coupling information, ${ }^{20}$ and that the magnitude of the coupling constant appeared to be dependent on molecular geometry, ${ }^{21-23}$ accelerated the efforts to find satisfactory theoretical models to describe molecular structures in solution. Today, experimental NMR data in conjunction with theoretical calculations and fitting procedures can provide a complete picture of a molecule's solution geometry. The general NMR structures of procyanidins have been reported before ${ }^{24-32}$ and molecular modeling studies as well. $24,27,28$

In all previously published studies concerning the solution conformation of procyanidins, the conclusion has been drawn that the inter-flavanol linkage between catechin or epicatechin units in $(4,8)$-linkages is subject to rotation and that the tetrahydropyran rings show different degrees of half-chair interconversion. In the present study we have used high-resolution variable-temperature NMR spectroscopy and molecular modeling to attempt a quantitative description of the solution conformations of procyanidin B1, B2, and C1. 


\section{Results and Discussion}

\section{NMR Analysis}

The complete structural assignment and solution conformation of (-)-epicatechin (1), Fig. 1) was obtained from ${ }^{1} \mathrm{H}-,{ }^{13} \mathrm{C}-,{ }^{1} \mathrm{H}-{ }^{1} \mathrm{H}-\mathrm{COSY},{ }^{1} \mathrm{H}-{ }^{13} \mathrm{C}-\mathrm{HMQC}$, and ${ }^{1} \mathrm{H}-{ }^{13} \mathrm{C}-\mathrm{HMBC}$ experiments as well as from $1 \mathrm{~d}-\mathrm{pfg}$-roesy experiments. In the half-chair conformation, the diastereotopic protons $\mathrm{H}_{R}$ and $\mathrm{H} 4_{s}$ resulted in coupling constants of ${ }^{3} \mathrm{~J}_{\mathrm{H} 4 \mathrm{R}, \mathrm{H} 3}=2.9 \mathrm{~Hz}$ and ${ }^{3} \mathrm{~J}_{\mathrm{H} 4 \mathrm{~S}, \mathrm{H} 3}=4.6 \mathrm{~Hz}$ (Table 1$)$.

Table 1. ${ }^{a}{ }^{1} \mathrm{H}-\mathrm{NMR}$ chemical shifts in ppm and coupling constants in $\mathrm{Hz}$ for (-)-epicatechin (1b), procyanidin $\mathrm{B} 1$ (2), B2 (3), and C1 (4) in MeOD. Compound 1b at rt; compounds 2-4 at $-15^{\circ} \mathrm{C}$.

\begin{tabular}{|c|c|c|c|c|c|c|c|c|}
\hline & \multirow[t]{2}{*}{$1 b$} & \multicolumn{2}{|c|}{2} & \multicolumn{2}{|c|}{3} & \multicolumn{3}{|c|}{4} \\
\hline & & A & B & A & B & A & B & C \\
\hline \multirow[t]{5}{*}{2} & 4.79 & 5.06 & 4.92 & 5.02 & 4.94 & 5.23 & 4.92 & 4.97 \\
\hline & $3 / 2,3 \sim 1$ & $3 / J_{2,3}<1$ & ${ }^{3} / 2,3=5.5$ & ${ }^{3} J_{2,3}<1$ & $3^{3} / 2,3<1$ & ${ }^{3} J_{2,3}<1$ & $3^{3} / 2,3<1$ & $3 / 2,3<1$ \\
\hline & (GIAO:1.3 & (GIAO:0.9 & (GIAO:5.6 & (GIAO:0.8 & (GIAO:0.8 & (GIAO:0.9 & (GIAO:0.8 & (GIAO:0.7 \\
\hline & $\mathrm{HLA}^{\mathrm{h}}: 0.8$ & $H_{L} A^{h}: 1.2$ & $\mathrm{HLA}^{\mathrm{h}}: 2.2$ & $\mathrm{HLA}^{\mathrm{h}}: 2.6$ & $\mathrm{HLA}^{\mathrm{h}}: 0.8$ & $\mathrm{HLA}^{\mathrm{h}}: 0.8$ & $\mathrm{HLA}^{\mathrm{h}}: 0.9$ & $H L A^{h}: 0.8$ \\
\hline & $\left.H L A^{\mathrm{sB}}: 1.1\right)$ & $\left.\mathrm{HLA}^{\mathrm{sB}}: 0.4\right)$ & $\left.H L A^{\mathrm{sB}}: 3.7\right)$ & $\left.H L A^{s B}: 0.3\right)$ & $\left.\mathrm{HLA}^{\mathrm{sB}}: 0.3\right)$ & $\left.H L A^{s B}: 0.3\right)$ & $\left.H L A^{s B}: 0.3\right)$ & $\left.H L A^{\mathrm{sB}}: 0.3\right)$ \\
\hline \multirow[t]{10}{*}{3} & 4.15 & 3.91 & 4.13 & 3.81 & 4.25 & 3.91 & 3.95 & 4.29 \\
\hline & $3_{3,2}=1.5$ & ${ }^{3} J_{3,2}<1$ & ${ }^{3} \int_{3,2}=5.4$ & ${ }^{3} \int_{3,2}<1$ & $3_{3,2}<1$ & $3_{3,2}<1$ & $3_{3,2}<1$ & ${ }^{3} J_{3,2}<1$ \\
\hline & $3_{3,4 R}=3.0$ & $3 J_{3,4}=1.1$ & $3 J_{3,4 R}=5.9 *$ & $3 J_{3,4}=1.5$ & ${ }^{3} J_{3,4 R}=3.7$ & $3 J_{3,4}=0.9$ & $3 J_{3,4}=1.1$ & $3 J_{3,4 R}=3.4$ \\
\hline & (GIAO:2.8 & (GIAO:1.9 & (GIAO:5.7 & (GIAO:1.6 & (GIAO:1.9 & (GIAO:1.5 & (GIAO:1.5 & (GIAO:1.8 \\
\hline & $H L A^{\mathrm{h}}: 2.3$ & $\mathrm{HLA}^{\mathrm{h}}: 2.2$ & $\mathrm{HLA}^{\mathrm{h}}: 4.4$ & $\mathrm{HLA}^{\mathrm{h}}: 4.4$ & $\mathrm{HLA}^{\mathrm{h}}: 2.5$ & $\mathrm{HLA}^{\mathrm{h}}: 1.2$ & $\mathrm{HLA}^{\mathrm{h}}: 1.3$ & $\mathrm{HLA}^{\mathrm{h}}: 2.3$ \\
\hline & $\left.H L A^{s B}: 3.7\right)$ & $\left.H L A^{\mathrm{sB}}: 2.0\right)$ & $\left.H L A^{s B}: 4.0\right)$ & $\left.H L A^{\mathrm{sB}}: 1.6\right)$ & $\left.H L A^{\mathrm{sB}}: 2.0\right)$ & $\left.H L A^{s B}: 1.0\right)$ & $\left.H L A^{\mathrm{sB}}: 1.0\right)$ & $\left.H L A^{\mathrm{sB}}: 1.8\right)$ \\
\hline & $3_{3,45}=4.5$ & & $3 J_{3,45}=4.5^{*}$ & & $3 J_{3,45}=3.7$ & & & $3 J_{3,45}=3.4$ \\
\hline & (GIAO:4.5 & & (GIAO:4.6 & & (GIAO:4.8 & & & (GIAO:5.5 \\
\hline & $\mathrm{HLA}^{\mathrm{h}}: 4.4$ & & $\mathrm{HLA}^{\mathrm{h}}: 3.2$ & & $\mathrm{HLA}^{\mathrm{h}}: 4.2$ & & & $\mathrm{HLA}^{\mathrm{h}}: 4.5$ \\
\hline & $\left.H L A^{s B}: 4.5\right)$ & & $\left.H L A^{\mathrm{sB}}: 2.3\right)$ & & $\left.\mathrm{HLA}^{\mathrm{sB}}: 4.5\right)$ & & & $\left.H L A^{s B}: 5.3\right)$ \\
\hline \multirow[t]{2}{*}{4} & - & 4.63 & - & 4.61 & - & 4.67 & 4.67 & - \\
\hline & & $3 J_{4,3}=1.2$ & & ${ }^{3} J_{4,3}=1.3$ & & $3_{4,3}=$ n.d. & $3 J_{4,3}=$ n.d. & \\
\hline \multirow[t]{4}{*}{$4 R$} & 2.71 & - & 2.58 & - & 2.78 & - & - & 2.79 \\
\hline & ${ }^{2} J_{4 R, 4 S}=-16.7$ & & ${ }^{2} J_{4 R, 4 S}=-17.0 *$ & & ${ }^{2} J_{4 R, 4 S}=-16.9$ & & & ${ }^{2} J_{4 R, 4 S}=-16.6$ \\
\hline & (GIAO:-14.9) & & (GIAO:-15.9) & & (GIAO:-15.4) & & & (GIAO:-17.2) \\
\hline & $3_{4 R, 3}=2.9$ & & & & ${ }^{3} J_{4 R, 3}<1$ & & & ${ }^{3} J_{4 S, 3}=1.5$ \\
\hline \multirow[t]{3}{*}{$4 s$} & 2.84 & - & 2.60 & - & 2.92 & - & - & 2.94 \\
\hline & ${ }^{2} J_{4 S, 4 R}=16.6$ & & ${ }^{2} J_{4 S, 4 R}=$ n.d & & ${ }^{2} J_{4 S, 4 R}=-16.9$ & & & ${ }^{2} J_{4 S, 4 R}=-16.7$ \\
\hline & ${ }^{3} J_{45,3}=4.6$ & & & & ${ }^{3} J_{45,3}=4.2$ & & & ${ }^{3} J_{4 s, 3}=4.5$ \\
\hline \multirow[t]{3}{*}{6} & 5.89 & 5.90 & 5.81 & 5.93 & 5.86 & 5.95 & 5.87 & 5.91 \\
\hline & ${ }^{4} J_{6,8}=2.3$ & ${ }^{4} J_{6,8}=2.3$ & & ${ }^{4} J_{6,8}=2.3$ & & ${ }^{4} J_{6,8}=2.1$ & & \\
\hline & (GIAO:2.5) & (GIAO:2.3) & & (GIAO:2.4) & & & & \\
\hline \multirow[t]{2}{*}{8} & 5.92 & 5.92 & - & 5.95 & - & 5.98 & - & - \\
\hline & ${ }^{4} / 8,6=2.3$ & ${ }^{4} J_{8,6}=2.3$ & & ${ }^{4} J_{8,6}=2.3$ & & ${ }^{4} J_{8,6}=2.1$ & & \\
\hline
\end{tabular}




\begin{tabular}{|c|c|c|c|c|c|c|c|c|}
\hline & \multirow[t]{2}{*}{$1 b$} & \multicolumn{2}{|c|}{2} & \multicolumn{2}{|c|}{3} & \multicolumn{3}{|c|}{4} \\
\hline & & A & B & A & B & A & B & C \\
\hline \multirow[t]{3}{*}{$2^{\prime}$} & 6.95 & 6.83 & 6.84 & 6.82 & 7.08 & 7.0 & 6.88 & 7.1 \\
\hline & ${ }^{4} J_{2^{\prime}, 6^{\prime}}=1.9$ & ${ }^{4} J_{2^{\prime}, 6^{\prime}}=1.1$ & ${ }^{4} J_{2^{\prime}, 6^{\prime}}=1.2$ & ${ }^{4} J_{2^{\prime}, 6^{\prime}}=1.7$ & ${ }^{4} J_{2^{\prime}, 6^{\prime}}=1.7$ & ${ }^{4} J_{2^{\prime}, 6^{\prime}}=1.6$ & ${ }^{4} J_{2^{\prime}, 6^{\prime}}=1.8$ & ${ }^{4} J_{2^{\prime}, 6^{\prime}}=1.6$ \\
\hline & (GIAO:1.9) & (GIAO:1.7) & (GIAO:2.0) & (GIAO:1.7) & (GIAO:1.8) & & & \\
\hline \multirow[t]{3}{*}{$5^{\prime}$} & 6.73 & 6.84 & 6.65 & 6.67 & 6.71 & 6.65 & 6.71 & 6.73 \\
\hline & ${ }^{2} J_{5^{\prime}, 6^{\prime}}=8.1$ & ${ }^{2} J_{5^{\prime}, 6^{\prime}}=7.9$ & $2 J_{5^{\prime}, 6^{\prime}}=7.9$ & $2 J_{5^{\prime}, 6^{\prime}}=8.2$ & ${ }^{2} J_{5^{\prime}, 6^{\prime}}=8.2$ & $2 J_{5^{\prime}, 6^{\prime}}=8.2$ & ${ }^{2} J_{5^{\prime}, 6^{\prime}}=8.7$ & ${ }^{2} J_{5^{\prime}, 6^{\prime}}=8.4$ \\
\hline & (GIAO:8.3) & (GIAO:8.7) & (GIAO:8.9) & (GIAO:8.8) & (GIAO:8.8) & & & \\
\hline \multirow[t]{3}{*}{$6^{\prime}$} & 6.77 & 6.84 & 6.87 & 6.61 & 6.85 & 6.69 & 6.69 & 6.88 \\
\hline & ${ }^{4} J_{6^{\prime}, 2^{\prime}}=2.0$ & ${ }^{4} J_{6^{\prime}, 2^{\prime}}=$ n.d. & ${ }^{4} J_{6^{\prime}, 2^{\prime}}<1$ & ${ }^{4} J_{6^{\prime}, 2^{\prime}}=1.7$ & ${ }^{4} J_{6^{\prime}, 2^{\prime}}=1.2$ & ${ }^{4} J_{6^{\prime}, 2^{\prime}}=1.8$ & ${ }^{4} J_{6^{\prime}, 2^{\prime}}=1.8$ & ${ }^{4} J_{6^{\prime}, 2^{\prime}}=1.7$ \\
\hline & ${ }^{2} J_{6^{\prime}, 5^{\prime}}=8.2$ & ${ }^{2} J_{6^{\prime}, 5^{\prime}}=$ n.d. & ${ }^{2} J_{6^{\prime}, 5^{\prime}}=7.9$ & ${ }^{2} J_{6^{\prime}, 5^{\prime}}=8.1$ & ${ }^{2} J_{6^{\prime}, 5^{\prime}}=8.7$ & ${ }^{2} J_{6^{\prime}, 5^{\prime}}=8.7$ & ${ }^{2} J_{6^{\prime}, 5^{\prime}}=8.5$ & ${ }^{2} J_{6^{\prime}, 5^{\prime}}=8.2$ \\
\hline
\end{tabular}

${ }^{a}$ Row 1: compound no. Row 2: component ring; Column 1: H measured; Theoretical J-values (GIAO) in parentheses were Boltzmann-weighted for $\mathbf{1 b}$ by 56:26:11:7 (at rt), for 2 by 50:24:15:11, for 3 by 47:32:13:9, and for 4 by 53.8:34.6:6.7:2.7. All values were corrected by a factor of $0.92 .{ }^{34}$ Theoretical J-values (HLA) ${ }^{35}$ in parentheses were weighted over the MD-histogram $\left(H L A^{h}\right)$ or were calculated from static Boltzmann-weighted $\left(\mathrm{HLA}^{\mathrm{sB}}\right)$ structures, *simulated J-value for major conformer(s), "n.d." = not determined.

Upon irradiation of $\mathrm{H} 2$, an rOe response at $\mathrm{H}_{4}$ ( $\left.1.2 \%\right)$ confirmed the preferred tetrahydropyran- ${ }^{2} \mathrm{H}_{3}$ conformation. Because the $\mathrm{H} 3-\mathrm{C} 3$-bond bisects the $\mathrm{H}-\mathrm{C}-\mathrm{H}$ bond angle of the two diastereotopic methylene protons $\mathrm{H}_{2}$ and $\mathrm{H}_{4}$ in the ${ }^{2} \mathrm{H}_{3}$-conformation, the resulting ${ }^{1} \mathrm{H}-{ }^{1} \mathrm{H}-J$-values were small to average.

However, the difference of approximately $1.5 \mathrm{~Hz}$ must clearly have resulted from a non-symmetrical environment of the protons. In addition, at room temperature, the structure underwent significant molecular motion resulting in non-symmetrical statistical angle distribution for $\mathrm{H} 4{ }_{R}-\mathrm{H} 3$ and $\mathrm{H} 4 s_{s}-\mathrm{H} 3$. Upon irradiation of $\mathrm{H} 2$, additional strong rOe responses were observed at the catechol protons $\mathrm{H}^{\prime}$ and $\mathrm{H}^{\prime}$, which indicated free bond rotation of the catechol ring. From the $J$-resolved ${ }^{1} \mathrm{H}-{ }^{13} \mathrm{C}-\mathrm{HMBC}$ spectrum of $\mathbf{1 b}$ heteronuclear coupling constants for diagnostic dihedral angles in the ${ }^{2} \mathrm{H}_{3}$-conformation were determined.

The error associated with the fitted values was $\pm 0.5 \mathrm{~Hz}$, which was determined from multiple measurements of cross-peak volumes and quality of subsequent fitting. Values of ${ }^{3} \mathrm{~J}_{\mathrm{H}-\mathrm{C} 10}=5.5 \mathrm{~Hz}\left(r^{2}=0.995\right)$, ${ }^{3} J_{\mathrm{H} 4 S-\mathrm{C} 2}=0.4 \mathrm{~Hz}\left(r^{2}=0.962\right)$, and ${ }^{3} J_{\mathrm{H} 4 R-\mathrm{C} 2}=5.3 \mathrm{~Hz}\left(r^{2}=0.999\right)$ were measured (Suppl. Information). These constitute precision of measurement and not necessarily accuracy. Unlike observed by us earlier for the chromenylium core of anthocyanins, ${ }^{33}$ no deuterium exchange was observed for $\mathrm{H} 6$ and $\mathrm{H} 8$ in the chroman system even after several months.

The structures of procyanidins feature several flavanoid units that are oxidatively connected between $\mathrm{C} 4$ (R-configuration) and C8. Procyanidin B1 (2) and B2 (3) have dimeric structures whereas procyanidin C1 (4) is a trimer. The $C 4_{R}-C 8$ linkage between two flavanoid units give rise to two theoretical rotamers, namely $(P)-2$ and (M)-2 (atropisomers) (Fig. 2). 
<smiles>Oc1cc(O)c2c(c1)O[C@H](c1ccc(O)c(O)c1)[C@H](O)C2c1c(O)cc(O)c2c1O[C@H](c1ccc(O)c(O)c1)[C@H](O)C2</smiles><smiles>Oc1cc(O)c2c(c1)O[C@H](c1ccc(O)c(O)c1)C(O)C2c1c(O)cc(O)c2c1O[C@H](c1ccc(O)c(O)c1)[C@H](O)C2</smiles>

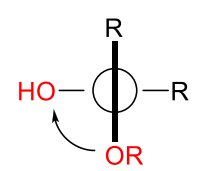

$(P)-2$

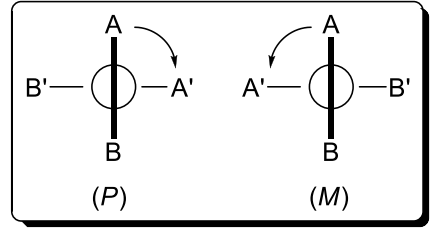

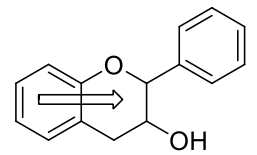

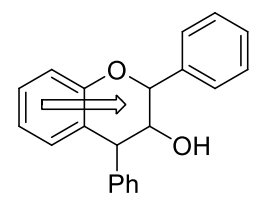

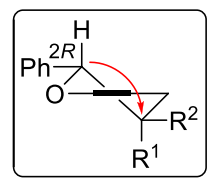

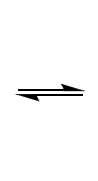

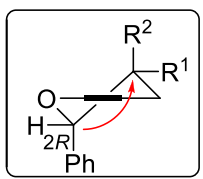

$\mathrm{Ph}$

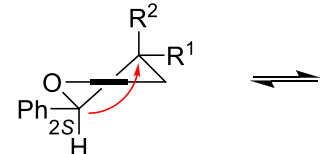

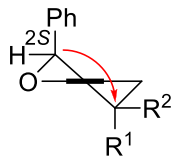

\begin{abstract}
${ }^{2} \boldsymbol{H}_{\mathbf{3}}$-conformer ("E-conformer") $(P)$-helicity $\rightarrow{ }^{1} \mathrm{~L}_{\mathrm{b}}$ negative $\mathrm{R}^{1}=\mathrm{OH}, \mathrm{R}^{2}=\mathrm{H}(2 R, 3 R)$, cis

${ }^{3} \boldsymbol{H}_{\mathbf{2}}$-conformer ("A-conformer") $(M)$-helicity $\rightarrow{ }^{1} \mathrm{~L}_{\mathrm{b}}$ positive $\mathrm{R}^{1}=\mathrm{OH}, \mathrm{R}^{2}=\mathrm{H}(2 R, 3 R)$, cis $\mathrm{R}^{1}=\mathrm{H}, \mathrm{R}^{2}=\mathrm{OH}(2 R, 3 S)$, trans

$\mathrm{R}^{1}=H, \mathrm{R}^{2}=\mathrm{OH}(2 R, 3 S)$,
\end{abstract}

${ }^{3} \boldsymbol{H}_{\mathbf{2}}$-conformer ("E-conformer") ${ }^{2} \boldsymbol{H}_{\mathbf{3}}$-conformer ("A-conformer") $(M)$-helicity $\rightarrow{ }^{1} \mathrm{~L}_{\mathrm{b}}$ positive $(P)$-helicity $\rightarrow{ }^{1} \mathrm{~L}_{\mathrm{b}}$ negative $\mathrm{R}^{1}=\mathrm{OH}, \mathrm{R}^{2}=\mathrm{H}(2 S, 3 R)$, trans $\mathrm{R}^{1}=\mathrm{OH}, \mathrm{R}^{2}=\mathrm{H}(2 S, 3 R)$, trans $\mathrm{R}^{1}=\mathrm{H}, \mathrm{R}^{2}=\mathrm{OH}(2 S, 3 S)$, cis $\quad \mathrm{R}^{1}=\mathrm{H}, \mathrm{R}^{2}=\mathrm{OH}(2 S, 3 S)$, cis

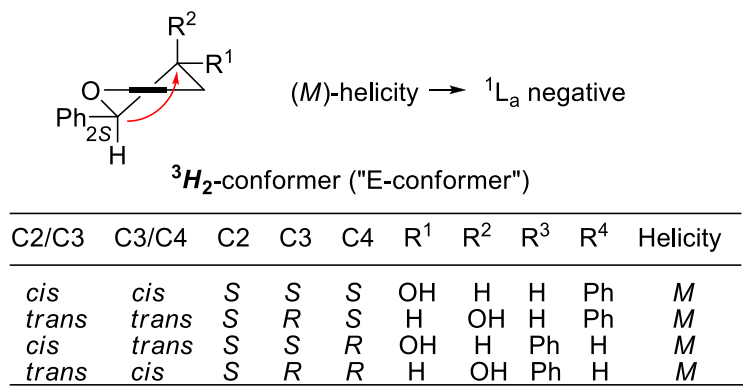

Figure 2. Top: Examples of atropisomers of procyanidin B1: [(P)-2] and [(M)-2]. The IUPAC nomenclature rules are based on perpendicularly-offset reference planes between the tetrahydropyran ring and the resorcinol ring. The nomenclature based on " $M$ " (minus) and " $P$ " (plus) is recommended rather than the $R / S$ nomenclature, which potentially leads to confusion with centro-chiral structural moieties; center: Definition of $(M)$ - and $(P)$-helicity of flavan-3-ols ${ }^{17}$ and its effect on the $C D$-absorption band ${ }^{1} L_{b}$ at $~ 260-280 \mathrm{~nm}$; bottom: Definition of $(M)$ - and $(P)$-helicity of 4 -aryl-flavan-3-ols ${ }^{17}$ and its effect on the $C D$-absorption band ${ }^{1} L_{a}$ at $\sim 220$ $240 \mathrm{~nm}$. The quadrant rule has been used to explain the CD spectra of procyanidins. ${ }^{18,36}$

Procyanidin B1 (2) was characterized by very broad spectral peaks that lacked fine-structure at room temperature (Fig. 3, top). At elevated temperatures $\left(+40^{\circ} \mathrm{C}\right)$, the line broadening became more significant. This indicated that at room temperature the structure underwent conformational changes close to the coalescence temperature on the NMR time scale. At low temperature $\left(-15^{\circ} \mathrm{C}\right)$ two distinct conformers of ratio $3: 1$, corresponding to an approximate difference in Gibbs Free Energy of $\Delta G=0.65 \mathrm{kcal} / \mathrm{mol}$, were frozen out. The ratio appeared constant at different temperatures suggesting a process dependent on enthalpy with minimal entropic penalty (Suppl. Material). In the tetrahydropyran ring A, all observed coupling constants were less than $1 \mathrm{~Hz}$ and not well resolved, consistent with a ${ }^{2} H_{3}$-conformation. In ring $B$, small coupling constants of ${ }^{3} J_{\mathrm{H} 4 \mathrm{~S}, \mathrm{H3}}=4.5 \mathrm{~Hz}$ (AB-mix, simulated) and ${ }^{3} \mathrm{~J}_{\mathrm{H} 4 \mathrm{R}, \mathrm{H3}}=5.9 \mathrm{~Hz}$ (AB-mix simulated) confirmed the preferred opposite tetrahydropyran ${ }^{3} \mathrm{H}_{2}$ conformation. 
The minor solution geometry displayed identical $J$-values for the ring $A$, whereas ring $B$ had undergone a change from ${ }^{3} \mathrm{H}_{2}$ to ${ }^{2} \mathrm{H}_{3}$ with coupling constants of ${ }^{3} J_{\mathrm{H} 4 R, \mathrm{H} 3}=5.6 \mathrm{~Hz}$ and ${ }^{3} J_{\mathrm{H} 4 \mathrm{~S}, \mathrm{H} 3}=8.9 \mathrm{~Hz}$ as well as ${ }^{2} J_{\mathrm{H} 4 R, \mathrm{H} 4 \mathrm{~S}}=16.0$ $\mathrm{Hz}$ in ring $\mathrm{B}$. This finding is markedly different from previously published studies of the same compound in water and in aqueous solution with low-alcohol content where the ${ }^{2} \mathrm{H}_{3}$ conformation of ring $\mathrm{B}$ was dominant at 95:5. ${ }^{27}$ Apparently, the solvent plays a critical role in the solution conformation of the tetrahydropyran ring. Therefore, previous studies of per-O-acetylated derivatives of $\mathbf{2}$ and, for that matter, any derivatized procyanidin in $\mathrm{CDCl}_{3}$ or other aprotic and/or non-polar solvents must be treated with caution when drawing conclusions about the native procyanidin in whose structures free hydroxyl groups and solvent interactions may play critical conformational roles.

In our study, several diagnostic nuclear Overhauser effect enhancements were observed in the structure of 2. Upon irradiation of $\mathrm{H}^{\mathrm{B}}$, an enhancement in the most deshielded aromatic region ( $\mathrm{H} 2^{\prime}[0.2 \%] / 6^{\prime}{ }^{\mathrm{B}}[1.3 \%]$ ) resulted (Fig. 3, top). The same enhancement was observed after irradiation of $\mathrm{H} 4^{\mathrm{A}}$ consistent with free rotation of the catechol ring. The latter nOe also pointed to a preferred $(M)$-atropconformation in 2. Irradiation of $\mathrm{H}^{\mathrm{A}}$ resulted in nOe-enhancements at the $\mathrm{H} 2^{\prime}$ [4.7\%]/6 ${ }^{\mathrm{A}}$ [4.2\%] resonances. Whether the halfchair inversion in ring $B$ of the minor solution geometry described above was the only conformational difference or whether it went along with a change in atropconformation along the inter-flavanol $\mathrm{C} 4_{R}$-C8linkage could not be confirmed. There has not been any convincing experimental evidence in the literature for the contribution of atropisomers to the solution geometry of native procyanidins. Circumstantial evidence for the presence of the $(P)$-rotamer in dimeric procyanidins with 2,3-cis-configuration in ring A was reported in the literature from NMR/circular dichroism studies. ${ }^{24,37}$ However, those studies relied on NMR integration of signals at room temperature, which most certainly resulted in erroneous species abundance and possible misinterpretation of CD-data.

Furthermore, had contributions from the $(P)$-atropisomer been of significance, separate sets of NMRsignals should have been reported. Because circularly polarized light is "chiral" and interacts in diastereomeric fashion with enantiomers (configurational or conformational), atropisomers of the same helicity can undergo conformational changes elsewhere in the molecule affecting the CD spectrum significantly. This might be especially important if the change in conformation occurs in a chrial entity such as the half-chair with multiple stereogenic carbons. Half-chair helicity and aromatic quadrant rule for 4-aryl-flavan-3-ols have been reviewed. ${ }^{18}$ The stereogenicity of $(P)$-/(M)-atrophelicity in combination with $(P) /(M)$-half-chair-helicity results in eight $\left(2^{3}\right)$ possible diastereomeric conformers for dimeric procyanidins, each of which with an expected characteristic NMR signature when frozen out. Contribution of $(P)$-/ $(M)$-atropisomerism to the solution geometry of $\mathbf{2}$ in methanol is questionable, especially because the rotational barrier around the inter-flavanol bond is much higher (estimated $30-35 \mathrm{kcal} / \mathrm{mol}$ by single bond rotation) than the barrier to half-chair inversion. Only two sets of NMR signals were observed in our experiment and all NMR signals were explained by half-chair inversion in ring $B$ alone. It would be a great coincidence if the NMR signature of the $(M)$ atropisomer, including ${ }^{2} \mathrm{H}_{3} /{ }^{3} \mathrm{H}_{2}$ inversion, were to be completely isochronous with that of the $(P)$-atropisomer, including ${ }^{2} \mathrm{H}_{3} /{ }^{3} \mathrm{H}_{2}$-inversion. All carbons were assigned with the help of ${ }^{1} \mathrm{H}-{ }^{13} \mathrm{C}-\mathrm{HMQC}$ and ${ }^{1} \mathrm{H}-{ }^{13} \mathrm{C}-\mathrm{HMBC}$ correlations. For compound 2, the HMBC correlations did not include the remarkable long-range correlations over four bonds between $\mathrm{H6} / 8$ and $\mathrm{C} 4$ as observed in (-)-1b (Fig. 1, Suppl. Material). 

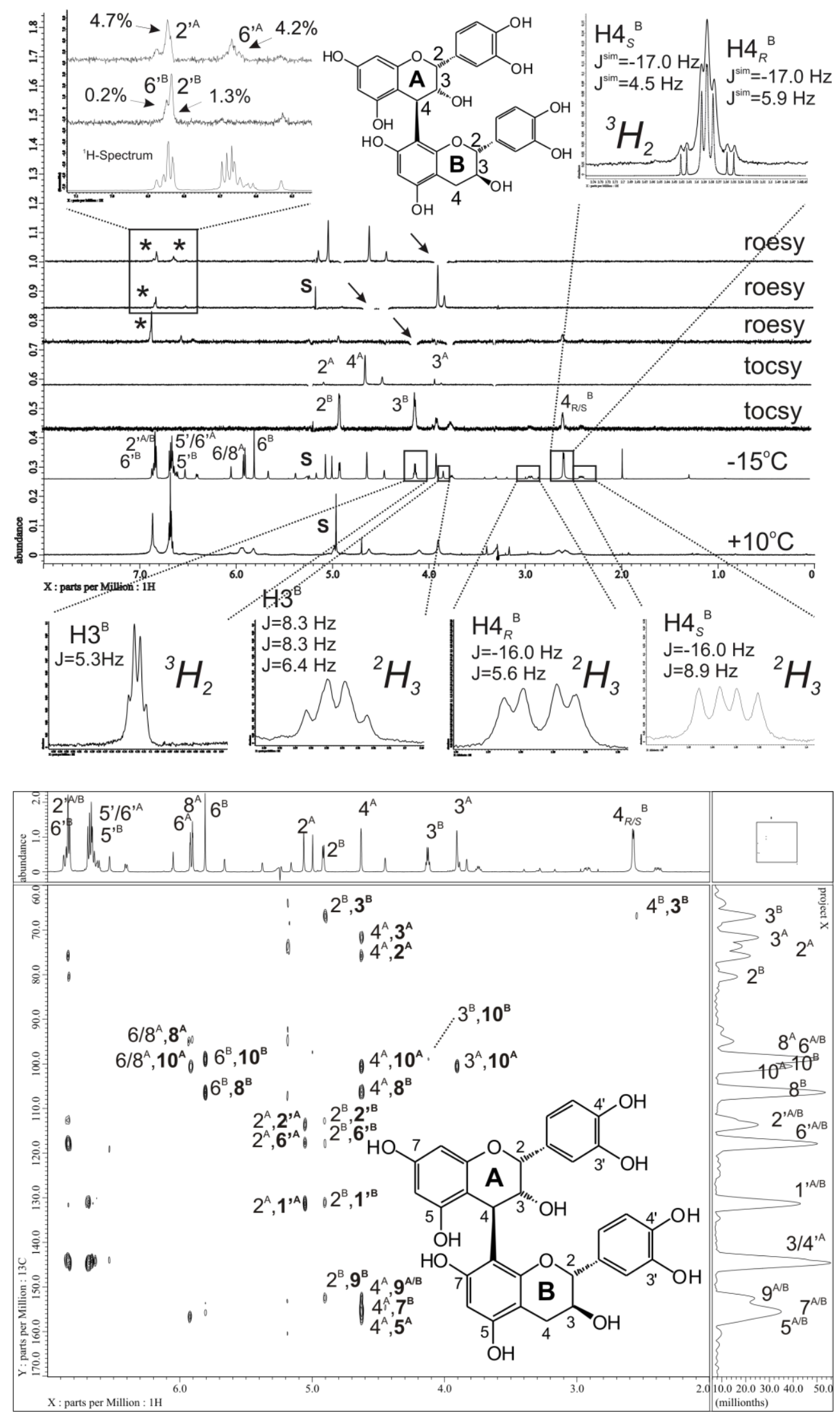

Figure 3. Top: VT-NMR spectra of 2. The insets show spectral details of the major solution conformer (signal of $\mathrm{H} 4_{R / S}$ simulated with TopSpin $3.5 \mathrm{pl} 7 \mathrm{NMRSim} 6.0$ module) and of the minor conformer (bottom right). Below: ${ }^{1} \mathrm{H}-{ }^{13} \mathrm{C}-\mathrm{HMBC}$ spectrum of $\mathbf{2}$. Carbon resonances in the tetrahydropyran rings were resolved whereas crosspeaks from the aromatic rings were overlapped. 
Likewise, we analyzed procyanidin $\mathrm{B} 2$ (3). Compound 3 is a $\mathrm{C} 3^{\mathrm{B}}$-epimer of procyanidin $\mathrm{B} 1$. At room temperature, the ${ }^{1} \mathrm{H}-\mathrm{NMR}$ spectrum of $\mathbf{3}$ was broad and mainly featureless, very similar to $\mathbf{2}$. Lowering the temperature to $-15{ }^{\circ} \mathrm{C}$ improved the appearance of the peaks and allowed the determination of several coupling constants (Fig. 4). Two distinct structural species in solution were observed at a ratio of 5:1, which corresponded to an approximate Gibbs free energy difference of $\Delta G=0.95 \mathrm{kcal} / \mathrm{mol}$. Also here, the ratio was constant and did not change with temperature, which suggested that the conformational change was enthalpy driven and nearly independent from entropic factors (Supplemental Material). In the major conformation, all $J$-values in the tetrahydropyran ring A were less than $1 \mathrm{~Hz}$ and indicated preference for the ${ }^{2} \mathrm{H}_{3}$-conformation, similar to 2 . In ring $B$, the signals of the diastereotopic protons $4_{R}$ and $4 s$ were only slightly $A B$-mixed with $J$ values of $4.6 \mathrm{~Hz}$ and $<1 \mathrm{~Hz}$ in their respective coupling to $\mathrm{H} 3$. Proton 3, in turn, was not entirely resolved with an estimated coupling constant of $\sim 3.7 \mathrm{~Hz}$ for both ${ }^{3} J_{3,45}$ and ${ }^{3} J_{3,2}$ in its triplet. Therefore, unlike compound 2 discussed above, ring $\mathrm{B}$ of $\mathbf{3}$ was in the ${ }^{2} \mathrm{H}_{3}$-conformation. Diagnostic rO-enhancements at the aromatic protons $2^{\prime B}$ and $6^{\prime B}$ upon irradiation of $\mathrm{H}^{\mathrm{A}}$ suggested that native 3 was present in solution as the $(M)$ atropisomer as previously reported for native $3^{30}$ and its acetylated analog. ${ }^{30,37}$ The minor solution conformation of $\mathbf{3}$ appeared to display identical half-chair conformations in both rings and suggested that the minor solution geometry was the result of inter-flavanol bond rotation. Whether the bond rotation caused the formation of $(M)$-/(P)-atropisomer populations or whether the bond rotation was limited to $\mathrm{H}$-bonded conformations within the $(M)$-atropisomer space could not be determined. Incidentally, the per-O-acetylated derivative of $\mathbf{3}$ had been investigated before in the literature with a $(M) /(P)$-atropisomer ratio of 1.5:1.0 based on circular dichroism in methanol and acetonitrile at $27{ }^{\circ} \mathrm{C} .{ }^{37}$ Unfortunately, no data for native 3 and no data at lower temperatures were reported. Based on the observed lack of temperature dependence of the conformational equilibrium and according to our results at $-15^{\circ} \mathrm{C}$ in methanol, native 3 appeared significantly biased in its conformational population ratio at 5:1. Even though methanol as a solvent is a hydrogen-bond competitor, the overall geometry of the procyanidin structure might still allow for favorable hydrogen bonds in native 3 that are absent in the acetylated analog. To the best of our knowledge, there has been no report of a crystal structure for native $\mathbf{3}$ or any analog thereof.

The CD-spectra of native $\mathbf{2}$ and $\mathbf{3}$ in methanol displayed large positive absorption ${ }^{1} \mathrm{~L}_{\mathrm{a}}$-bands as predicted by the aromatic quadrant rule and $(P)-{ }^{2} H_{3}$-helicity of ring $A$ (Supplemental Material). ${ }^{18}$ In addition, the ${ }^{1} L_{b}$-band of 2 was slightly positive, consistent with dominant but not exclusive $(M)-{ }^{3} \mathrm{H}_{2}$-conformation in ring $\mathrm{B}$ whereas the ${ }^{1} L_{b}$-band in the spectrum of 3 was negative, which matched the more abundant $(P)-{ }^{2} H_{3}$-conformation in ring $B$ (Supplemental Material).

Procyanidin $\mathrm{C} 1$ is a $\left(4_{R}, 8\right)$-linked trimer of $(-)$-epicatechin and was also characterized by broad featureless NMR signals at $r t$ that became sharp upon cooling to $-15^{\circ} \mathrm{C}$ (Fig. 5).

The ${ }^{1} \mathrm{H}-{ }^{13} \mathrm{C}-\mathrm{HMBC}$ confirmed the 4,8-linkage. However, unlike 1, 2, and 3 above, long-range correlations between $\mathrm{H} 3$ and $\mathrm{H} 6$ were absent (Supplemental Material). Ring $\mathrm{C}$ preferred the ${ }^{2} \mathrm{H}_{3}$ conformation because of small coupling constants between $\mathrm{H} 3$ and both diastereotopic protons $4_{R}$ and $4 s(1.5 \mathrm{~Hz}$ and $4.5 \mathrm{~Hz}$, respectively). Rings $\mathrm{A}$ and $\mathrm{B}$ were in the ${ }^{2} \mathrm{H}_{3}$-conformation as well with small coupling constants between $\mathrm{H} 2$, $\mathrm{H} 3$, and $\mathrm{H} 4$. At least two minor solution geometries at a ratio of $16: 2: 1(\Delta \mathrm{G}=1.3 \mathrm{kcal} / \mathrm{mol}$ and $1.7 \mathrm{kcal} / \mathrm{mol})$ relative to the major conformation were observed. The minor conformations did not appear to include halfchair ring inversion based on coupling constant analysis and were possibly atropisomers with respect to one or both inter-flavanol linkages. There was insufficient abundance of the minor species to allow unambiguous conformational analysis by NMR. For the major solution geometry, diagnostic nO-enhancements were observed at $\mathrm{H} 2^{\mathrm{B}}$ and $\mathrm{H} 6^{\mathrm{B}}$ upon irradiation of $\mathrm{H} 2^{\mathrm{B}}$, which was consistent with free rotation of the catechol rings as observed previously in $\mathbf{2}$ and $\mathbf{3}$ (Fig. 5, top). In addition, a weaker enhancement was recorded at $\mathrm{H}^{\prime}{ }^{\mathrm{A}}$. 
When the two protons 3 in ring $A$ and $B$ were irradiated simultaneously, the analogous enhancements at $H 2^{\prime} A$ and $\mathrm{H}^{\prime} \mathrm{A}$ as well as $\mathrm{H} 2^{\mathrm{B}}$ and $\mathrm{H}^{\prime}{ }^{\mathrm{B}}$ were observed. Aside from the catechol protons of $\mathrm{A}$ and $\mathrm{B}$, weak enhancement was also observed for $\mathrm{H}^{\prime}{ }^{\mathrm{C}}$ and $\mathrm{H6}^{\prime} \mathrm{C}$, which was interesting.

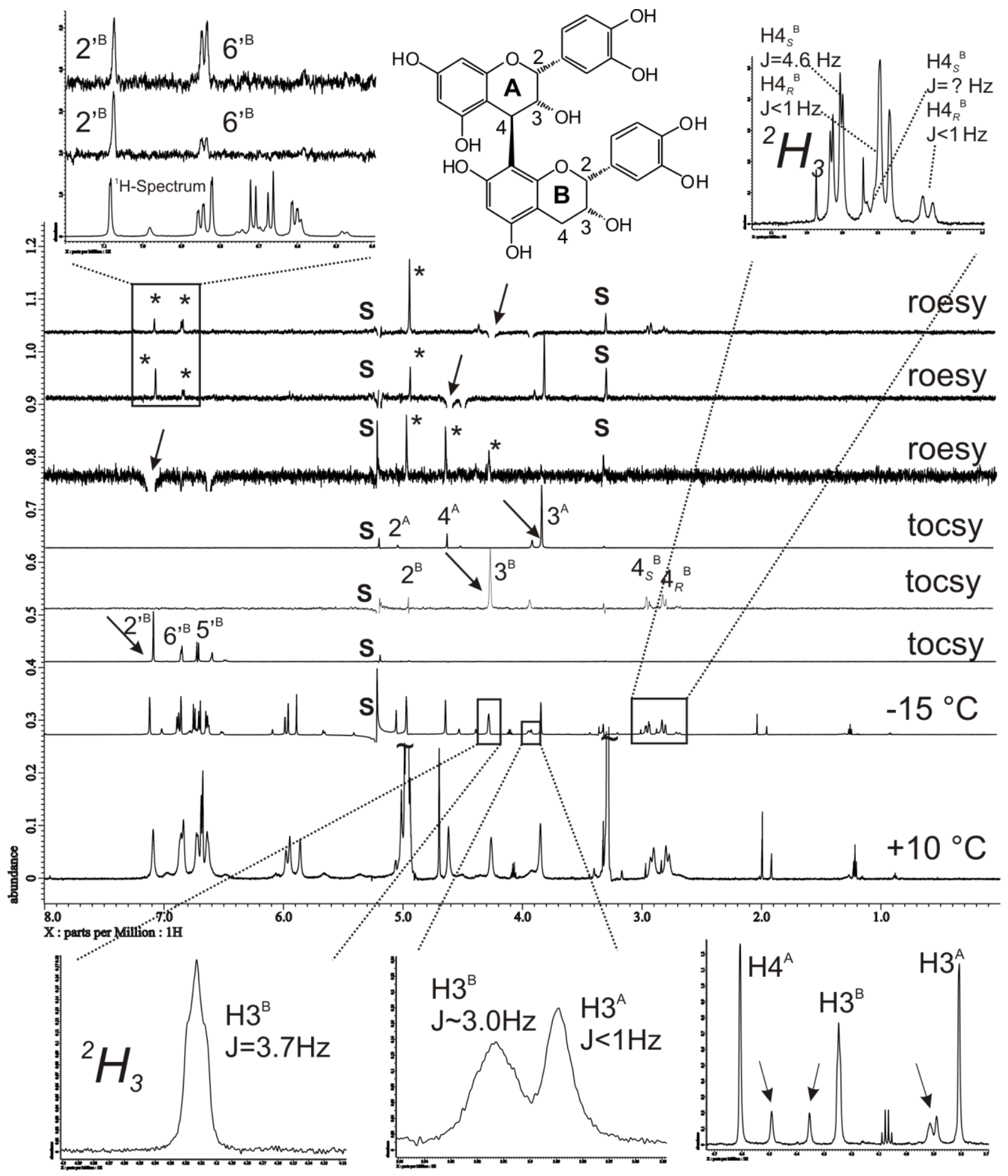

Figure 4. VT-NMR spectra of 3. At low temperature and independent from temperature, two distinct conformers of ratio 5:1, corresponding to an approximate difference in Gibbs Free Energy of $\Delta \mathrm{G}=0.95$ $\mathrm{kcal} / \mathrm{mol}$, were frozen out. Small coupling constants of ${ }^{3} \mathrm{~J}_{\mathrm{H} 4 \mathrm{a}, \mathrm{H} 3}=4.6 \mathrm{~Hz}$ and ${ }^{3} \mathrm{~J}_{\mathrm{H} 4 \mathrm{~b}, \mathrm{H} 3}<1 \mathrm{~Hz}$ confirmed the ${ }^{2} \mathrm{H}_{3}$ conformation in ring $\mathrm{B}$. The minor conformer was not unambiguously established, but appeared to have the same conformation in ring $B$ as the major conformer $\left({ }^{3} \mathrm{H}_{\mathrm{Ha}, \mathrm{H} 3}=\mathrm{n}\right.$. det. and $\left.{ }^{3} \mathrm{~J}_{\mathrm{H} 4 \mathrm{~b}, \mathrm{H} 3}<1 \mathrm{~Hz}\right)($ arrows$)$. 


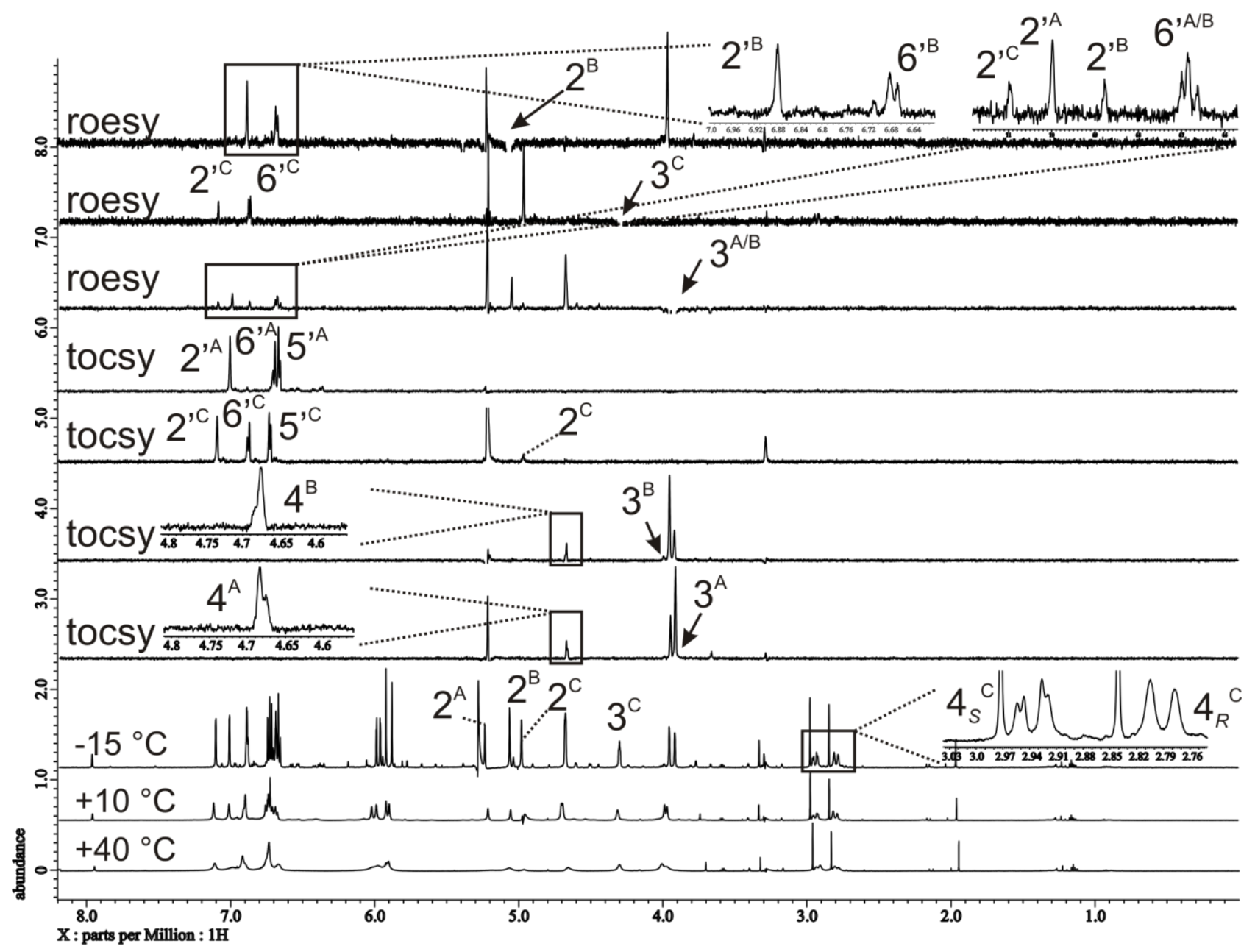

Figure 5. VT-NMR spectra of 4. At low temperature (slow exchange regime) at least three different distinct conformers of ratio 16:2:1, corresponding to an approximate difference in Gibbs Free Energy of $\Delta \mathrm{G}=1.3$ $\mathrm{kcal} / \mathrm{mol}$ and $1.7 \mathrm{kcal} / \mathrm{mol}$, were frozen out. Small coupling constants of ${ }^{3} \mathrm{~J}_{\mathrm{HRR} / \mathrm{s}^{\mathrm{C}}, \mathrm{H} 3}{ }^{\mathrm{C}}=3.2 \mathrm{~Hz}$ and ${ }^{3} \mathrm{H}_{\mathrm{H} 2}{ }^{\mathrm{C}}{ }_{\mathrm{H} 3}{ }^{\mathrm{C}}=5.3$ $\mathrm{Hz}$ confirmed the tetrahydropyran ${ }^{2} \mathrm{H}_{3}$ conformation, like ring $\mathrm{B}$ in $\mathbf{3}$ and unlike ring $\mathrm{B}$ in $\mathbf{2}$ (vide supra).

\section{Molecular Modeling}

(-)-Epicatechin (1b) has been modeled before in PCMODEL (GMMX search) based on NMR data. ${ }^{28}$ We confirmed that in the AMBER force field, the half-chair of $\mathbf{1 b}$ preferred the ${ }^{2} \mathrm{H}_{3}$-conformation exclusively (Supplemental Material). The catechol ring showed significant rotation, which resulted in conformations with sub- $3 \AA$ distances between $\mathrm{H} 2$ and $\mathrm{H}^{\prime} / \mathrm{H}^{\prime}$ consistent with the observed rO-enhancements.

To confirm the obtained results from MD-simulation, we chose the four most frequent conformations of 1b from the MD-trajectory and minimized them at progressively higher level of theory. A total of four conformations with relative energies of $0.00 \mathrm{kcal} / \mathrm{mol},+0.45 \mathrm{kcal} / \mathrm{mol},+0.96 \mathrm{kcal} / \mathrm{mol}$, and $+1.24 \mathrm{kcal} / \mathrm{mol}$ were identified. The lowest-energy structure of $\mathbf{1 b}$ with ${ }^{2} \mathrm{H}_{3}$-conformation displayed static dihedral angles for $\mathrm{H} 4 R_{R}-\mathrm{H} 3$ and $\mathrm{H}_{4} S^{-} \mathrm{H} 3$ of $\sim_{-} 75^{\circ}$ and $\sim_{+42^{\circ}}$, respectively. The minimized structure with the inverted ${ }^{3} \mathrm{H}_{2^{-}}$ conformation was found to be $0.96 \mathrm{kcal} / \mathrm{mol}$ less stable than the ${ }^{2} \mathrm{H}_{3}$-conformation, well within the range of thermal energy available at room temperature. The dihedral angles for $\mathrm{H} 4{ }_{R}-\mathrm{H} 3$ and $\mathrm{H} 4 s_{s}-\mathrm{H} 3$ were $\sim_{-170^{\circ}}$ and $\sim_{-}$ $53^{\circ}$, respectively. From the four conformations, the equilibrium concentrations of both half-chairs were calculated at a ratio of 82:18 according to Boltzmann statistics. However, the experiment had revealed only 
one NMR signal set at room temperature, which suggested that the half-chair inversion was fast at $-15^{\circ} \mathrm{C}$. Therefore, the notion of non-symmetrical gauche angles for the two angles as described above was valid.

For each of the lowest energy structures NMR-GIAO calculations were carried out and the obtained ${ }^{1} \mathrm{H}-{ }^{1} \mathrm{H}-$ and ${ }^{1} \mathrm{H}-{ }^{13} \mathrm{C}$-coupling constants (Fermi contact only) were weighted to result in theoretical $J$-values (Table 1 ). Initial calculations at the $\mathrm{M05}-2 \mathrm{x} / 6-31 \mathrm{G}^{* *}(\mathrm{u}+1 \mathrm{~s})$-level resulted in poor agreement with the experiment. However, when we used the B3LYP/6-311G** $(d, p)(u+1 s)$-method, a much better fit for Boltzmann-weighted ${ }^{1} \mathrm{H}-{ }^{1} \mathrm{H}$-couplings including correction factors ${ }^{34}$ (Table 1 ) and ${ }^{1} \mathrm{H}-{ }^{13} \mathrm{C}$-couplings without corrections were obtained. For the latter, values of ${ }^{3} J_{\mathrm{H} 3-\mathrm{C} 10}=5.3 \mathrm{~Hz},{ }^{3} \mathrm{~J}_{\mathrm{H} 4 \mathrm{~S}-\mathrm{C} 2}=1.3 \mathrm{~Hz}$, and ${ }^{3} \mathrm{~J}_{\mathrm{H} 4 \mathrm{R}-\mathrm{C} 2}=5.0 \mathrm{~Hz}$ were calculated, in excellent agreement with the experiment. Overall, our approach to the theoretical modeling of $\mathbf{1 b}$ was validated by the results and provided a protocol for the modeling of oligomers 2, 3, and 4 .

From the MD-trajectory of compound 2, a total of four low-energy structures were identified and minimized at progressively higher level of theory. Their relative energies were $0.00,+0.45,+0.70$, and +0.90 $\mathrm{kcal} / \mathrm{mol}$. The first two structures differed only in the relative orientation of the catechol rings and had ${ }^{2} \mathrm{H}_{3}-$ conformation in ring $\mathrm{A}$ and ${ }^{3} \mathrm{H}_{2}$-conformation in ring $\mathrm{B}$. The latter was inverted to a ${ }^{2} \mathrm{H}_{3}$-conformation in the third and fourth structure whose overall geometries were only different by catechol ring rotation. The three dihedral angles $\mathrm{H} 3-\mathrm{C} 3-\mathrm{C} 4-\mathrm{H} 4_{R / S}$ (rings $\mathrm{A}+\mathrm{B}$ ) and $\mathrm{C} 3^{\mathrm{A}}-\mathrm{C} 4^{\mathrm{A}}-\mathrm{C} 8^{\mathrm{B}}-\mathrm{C} \mathrm{B}^{\mathrm{B}}$ were indicators of any changes in the halfchair conformation in rings $A$ and $B$ as well as of rotational changes between the two flavanol units. The 2DRamachandran plot of the MD-trajectory showed that the dihedral angle $\mathrm{H} 3-\mathrm{C} 3-\mathrm{C} 4-\mathrm{H} 4$ ( $\mathrm{ring} \mathrm{A},{ }^{2} \mathrm{H}_{3}$ ) displayed a value around $-83^{\circ}$ and minor contributions from near anti-periplanar alignment from the other half-chair (5:1) (Fig. 6).
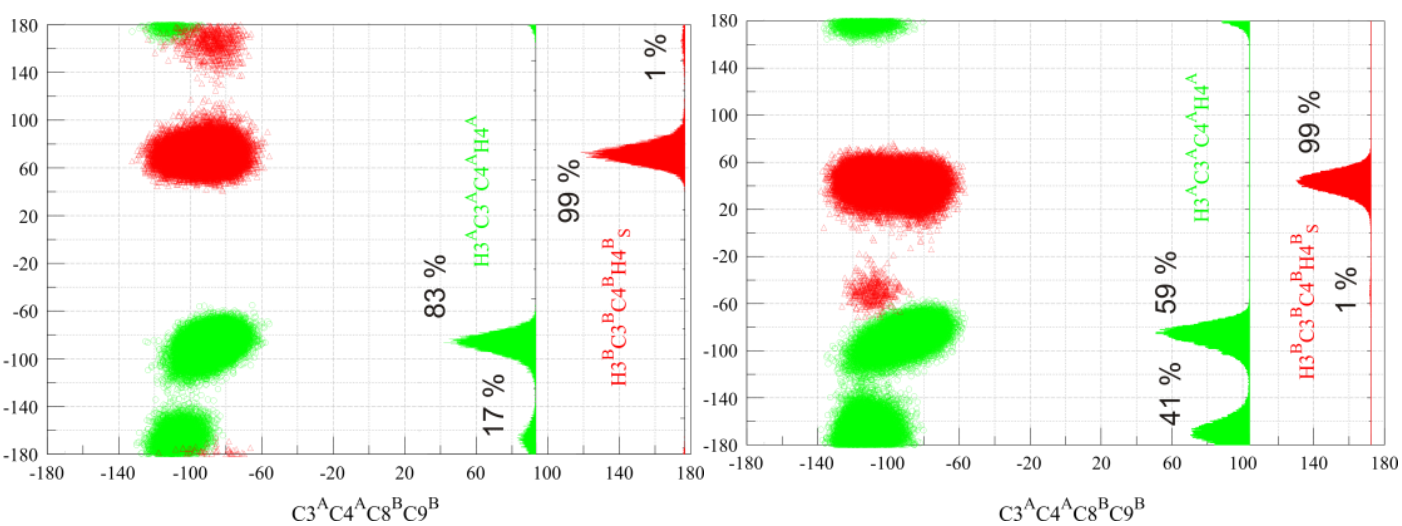

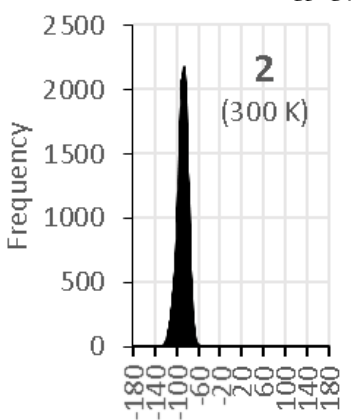

Dihedral angle $\left[^{\circ}\right]$

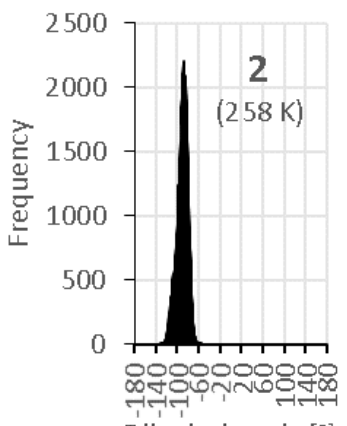

Dihedral angle [ $\left.{ }^{\circ}\right]$
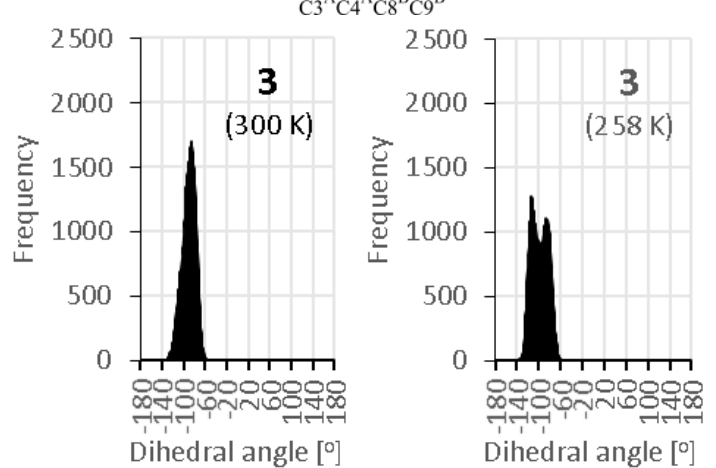

Figure 6. Ramachandran plot and 2D-histogram projections for two diagnostic dihedral angles describing the half-chair in ring $A$ (green, 0 ) and $B$ (red, $\Delta$ ) versus the dihedral angle $C 3^{A} C 4^{A} C 8^{B} C 9^{B}$ between the flavanol units in 2 (left) and 3 (right) at $258 \mathrm{~K}$. No significant inter-flavanol bond rotation from $(M)$ to $(P)$ was observed (Supplemental Material) in either $\mathbf{2}$ or $\mathbf{3}$ although two distinct populations around $-80^{\circ}$ and $-110^{\circ}$ were visible for $\mathbf{3}$ at low temperature. 
The corresponding angle in the ${ }^{3} \mathrm{H}_{2}$-conformation of ring $\mathrm{B}$, i.e. $\mathrm{H} 3-\mathrm{C} 3-\mathrm{C} 4-\mathrm{H} 4$ s, was centered around $+75^{\circ}$ with minor contributions at $+170^{\circ}$ from the opposite chair ( 99:1). In comparison to the exclusive experimental ${ }^{2} \mathrm{H}_{3}$-conformation in ring $\mathrm{A}$ and an experimental ${ }^{3} \mathrm{H}_{2}:{ }^{2} \mathrm{H}_{3}$-ratio of $3: 1$ in ring $\mathrm{B}$, only the general conformational preference of the half-chairs was modeled correctly for both rings in 2 by the MD-simulation. However, ring $A$ appeared to undergo more interconversion during $M D$ than the experiment suggested, whereas ring $B$ was more rigid than observed experimentally. This appeared to be a consequence of non-ideal force field parametrization.

Exclusive preference for the $(M)$-atrop rotamer was in agreement with the experimental observations described above. Interestingly, the conformation of the dihedral angle between the two flavanoid units $\left(\mathrm{C} 3^{\mathrm{A}}\right.$ $\mathrm{C} 4^{\mathrm{A}}-\mathrm{C} 8^{\mathrm{B}}-\mathrm{C} \mathrm{9}^{\mathrm{B}}$ ) did not display any significant temperature dependence (Fig. 6, bottom). As an additional control experiment, we generated the MD-trajectory of $\mathbf{2}$ in the $(P)$-atrop conformation. No interconversion to $(M)$ - $\mathbf{2}$ was observed and the lowest energy conformer identified was $+3.81 \mathrm{kcal} / \mathrm{mol}$ higher in energy than the lowest energy conformer of (M)-2 (Suppl. Material).

The distance histograms between $\mathrm{H}^{\mathrm{B}}$ and $\mathrm{H} 2^{\prime} / 6^{\prime}{ }^{\mathrm{B}}$, between $\mathrm{H} 3 / 4^{\mathrm{A}}$ and $\mathrm{H} 2^{\prime} / 6^{\prime}{ }^{\mathrm{B}}$, and between $\mathrm{H} 3^{\mathrm{A}}$ and $\mathrm{H} 2^{\prime} / 6^{\prime A}$ were constructed (Fig. 7, top two rows) and supported the experimentally observed rO-enhancements (Fig. 3) with significant sub-3Å distances. While the general trends observed in MD-simulation agreed with the experiment, an accurate and quantitative description of the solution geometry, however, was not achieved. However, overall dominance of the $(M)$-atroprotamer was correctly reflected in the MD-trajectory and was consistent with our nOe-data.
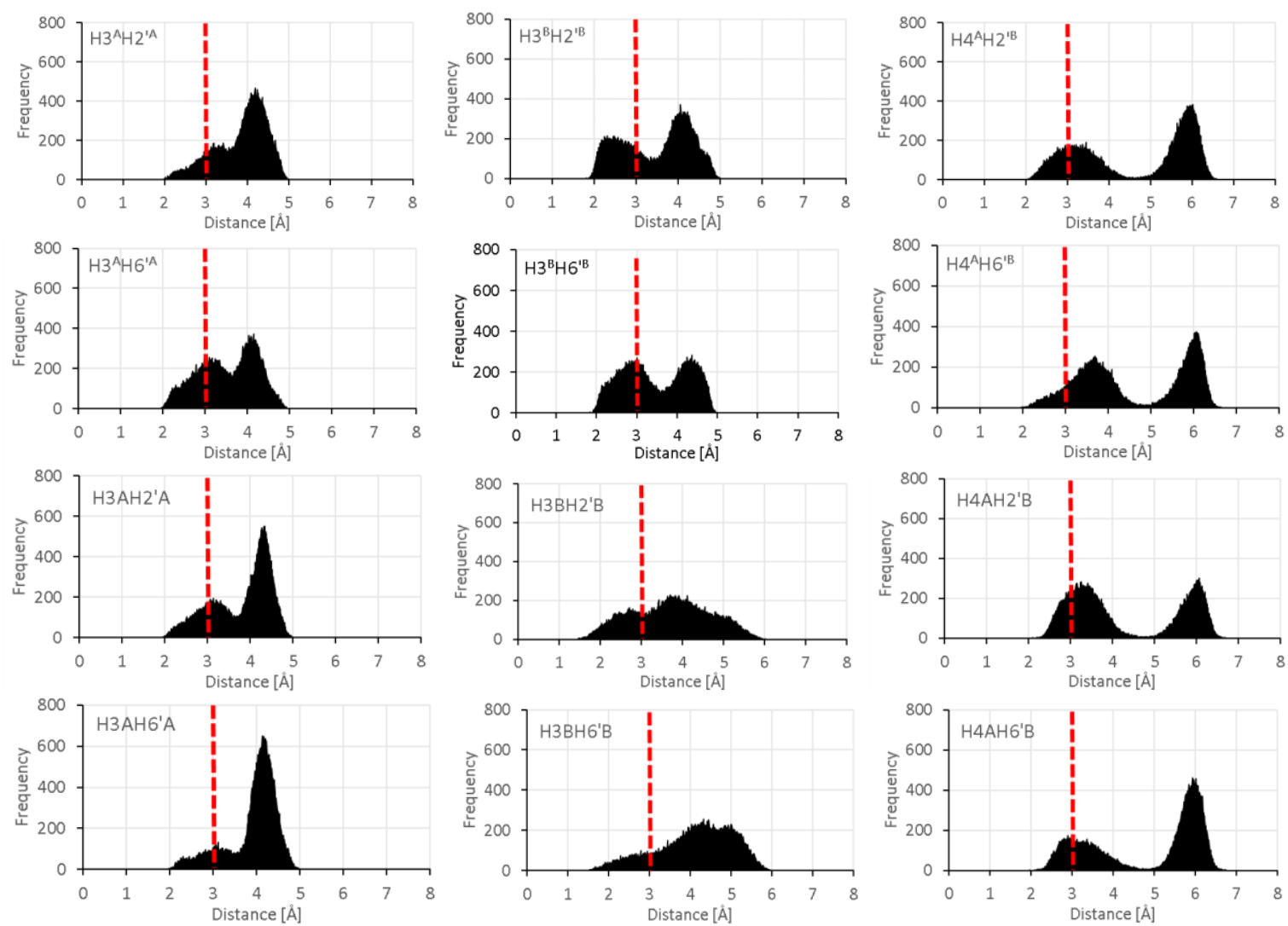

Figure 7. Distance histograms from MD-simulation of the most stable conformer of $\mathbf{2}$ (top two rows) and $\mathbf{3}$ (bottom two rows) at $258 \mathrm{~K}\left(-15^{\circ} \mathrm{C}\right)$ were consistent with rO-enhancement for proton pairs with significant populations of distances less than $3 \AA$. 
The General AMBER Force Field (GAFF) parameters including explicit solvent molecules were not optimal for the procyanidin system and will require adjustment to reflect the NMR data quantitatively. It is important to point out that GAFF has been used in previous attempts at molecular modeling of polyphenols. ${ }^{38-42}$ Quantitative results, therefore, have to be treated cautiously.

Whereas NMR spectroscopy has been used to investigate the structure of procyanidins in solution, X-Ray crystallography has provided insight into the solid state structure. One paper in the literature describes the $X-$ Ray single crystal structure of $(P)-2$ (ring $A:{ }^{2} H_{3}$, ring $B:{ }^{2} H_{3}$ ) whose hydroxyl groups as sources of intramolecular hydrogen bonding were acetylated altering the structure of native $2 .{ }^{15}$ Therefore, statements about native $\mathbf{2}$ in the crystalline state can only be made tentatively and by analogy only. Direct comparison to the solution geometry of native (M)-2 is not strictly possible because specific inter-molecular packing forces in the solid state apparently do allow inter-flavanol bond rotation to occur. In solution, however, this might be not possible. The circular dichroism behavior of acetylated 2 has also been described in the literature. ${ }^{37}$ The measurements were made at $27{ }^{\circ} \mathrm{C}$ and NMR data were collected at $200 \mathrm{MHz}$. A strong $20: 1$ preference for the $(M)$-rotamer was reported. However, because of chemical modification and non-natural solvent $\left(\mathrm{CDCl}_{3}\right)$, no inference can be made for native $\mathbf{2}$ in aqueous or strongly polar medium such as methanol.

In light of low-temperature measurements at high field and molecular modeling described above, we propose that the minor solution geometry of native $\mathbf{2}$ in methanol is the consequence of half-chair inversion in ring $B$ rather than change in helicity around the inter-flavanol linkage (Table 2). Both conformations display inter-flavanol (M)-helicity (Fig. 8). It is reasonable to assume that the conformational behavior of $\mathbf{2}$ in water is similar compared to that in methanol.

Table 2. Energy differences, helicities (Fig. 3) and Boltzman populations for conformations at the M05-2x/6$31 \mathrm{G}^{* *}$-level of theory with thermal correction (258 K) for 2-4.

\begin{tabular}{|c|c|c|c|c|c|c|}
\hline & ${ }^{2} H_{3}$ & ${ }^{3} \mathrm{H}_{2}$ & $(M)$ & $(P)$ & $\begin{array}{c}\Delta \mathbf{G} \\
{[\mathrm{kcal} / \mathrm{mol}]}\end{array}$ & $\begin{array}{c}\text { Abundance } \\
{[\%]}\end{array}$ \\
\hline $1 b(I)$ & + & - & & & 0.00 & 55.9 \\
\hline 1b (II) & + & - & & & +0.45 & 26.1 \\
\hline 1b (III) & - & + & & & +0.96 & 11.1 \\
\hline 1b (IV) & - & + & & & +1.24 & 6.9 \\
\hline $2(I)$ & $A$ & B & $A-B$ & - & 0.00 & 50.2 \\
\hline $2(I I)$ & $A$ & B & $A-B$ & - & +0.45 & 23.5 \\
\hline 2 (III) & $A, B$ & - & $A-B$ & - & +0.70 & 15.4 \\
\hline 2 (IV) & $A, B$ & - & $A-B$ & - & +0.90 & 11.0 \\
\hline $3(1)$ & $A, B$ & - & $A-B$ & - & 0.00 & 46.8 \\
\hline 3 (II) & $A, B$ & - & $A-B$ & - & +0.23 & 31.7 \\
\hline 3 (III) & $A, B$ & - & $A-B$ & - & +0.78 & 12.5 \\
\hline 3 (IV) & $A, B$ & - & A-B & - & +0.98 & 8.9 \\
\hline $4(I)$ & $A, B, C$ & - & $A-B, B-C$ & - & 0.00 & 53.8 \\
\hline 4 (II) & $A, B, C$ & - & $A-B, B-C$ & - & +0.25 & 34.6 \\
\hline 4 (III) & $A, B, C$ & - & $A-B, B-C$ & - & +1.22 & 6.7 \\
\hline 4 (IV) & $A, B, C$ & - & $A-B, B-C$ & - & +1.76 & 2.7 \\
\hline $4(V)$ & $A, B, C$ & - & $A-B, B-C$ & - & +2.19 & 1.3 \\
\hline $4(\mathrm{VI})$ & $A, B, C$ & - & $A-B, B-C$ & - & +2.22 & 1.2 \\
\hline 4 (VII) & $A, B, C$ & - & $A-B, B-C$ & - & +2.63 & 0.6 \\
\hline
\end{tabular}



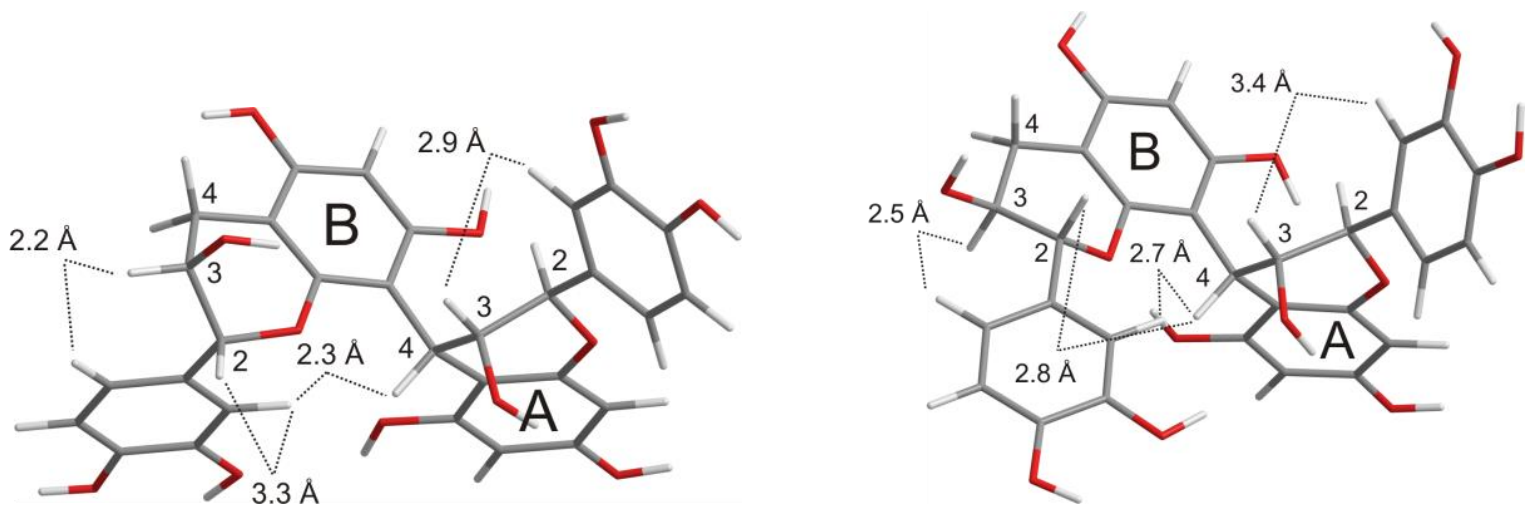

Figure 8. The lowest-energy conformation of $(M)-2\left(\mathrm{~A}:{ }^{2} \mathrm{H}_{3}, \mathrm{~B}:{ }^{3} \mathrm{H}_{2}\right)$ (left) and the third-lowest conformation $(M)-2$ at $+0.70 \mathrm{kcal} / \mathrm{mol}\left(\mathrm{A}:(M)-{ }^{3} \mathrm{H}_{2}, \mathrm{~B}:(P)-{ }^{2} \mathrm{H}_{3}\right)$ (right) at the M05-2x/6-31G**-level of theory with thermal correction (258 K) (Table 2). The energy difference of $\Delta \mathrm{G}=0.70 \mathrm{kcal} / \mathrm{mol}$ was in excellent agreement with the experimental frozen conformer ratio of 3:1 (Fig. 4).

Compound $\mathbf{3}$ was subjected to the same MD-simulation protocol. Analogous to 2, the helicity of $\mathbf{3}$ did not deviate from $(M)$ throughout the simulation at $258 \mathrm{~K}$ (Fig. 6, top right). However, unlike 2, the MD-trajectory of the inter-flavanol dihedral angle in $\mathbf{3}$ was distinctly split into two sub-populations at around $-60^{\circ}$ and $-110^{\circ}$ at $258 \mathrm{~K}$ whereas at $300 \mathrm{~K}$ the populations merged into one (Fig 6, bottom). This was presumably due to steric demand of the B-catechol ring, which was displayed pseudo-axially in $\mathbf{2}$ compared to $\mathbf{3}$. Even though methanol is commonly known as a "hydrogen-bond competitor", it appeared that in the case of $\mathbf{3}$, hindered interflavanol bond rotation made conformational $(M)$ sub-populations stabilized by multiple $\mathrm{H}$-bonds possible. Circumstantial evidence from the static energy-minimized structures suggested that this effect might not have been operational in $\mathbf{2}$ where the altered configuration at $\mathrm{C}^{\mathrm{B}}$ and opposite ${ }^{3} \mathrm{H}_{2}$-half-chair did reduced the number of favorable $\mathrm{H}$-bonds. We found that among the four structures of $\mathbf{2}$, the number of $\mathrm{H}$-bonds decreased from five $\mathrm{H}$-bonds in the most stable conformation to four in the second conformation and to three in the two less stable conformations (Supplemental Material). On the other hand, in $\mathbf{3}$ the intra-molecular $\mathrm{H}$ bond number stayed constant at four for all conformations (Supplemental Material). Ring $A$ in 3, whose configuration was the same as ring $A$ in $\mathbf{2}$, displayed a greater extent of half-chair interconversion (59:41). As such, half-chair interconversion observed during MD-simulation did not accurately reflect the experimental data. However, ring $\mathrm{B}$ in 3 did not deviate from its ${ }^{2} \mathrm{H}_{3}$-conformation (Fig. 6, top right) consistent with the experiment.

As an additional control experiment, we generated the MD-trajectory of $\mathbf{3}$ in the $(P)$-atrop conformation. Similar to 2, no transition to the $(M)$-conformer was observed. The lowest energy $(P)$-3 conformer identified was $+3.40 \mathrm{kcal} / \mathrm{mol}$ higher in energy than the lowest energy conformer of $(M)$-3 (Supplemental Material).

We propose that the minor solution geometry of $\mathbf{3}$ in methanol is not a consequence of inter-flavanol bond rotation leading to $(M)$ - and $(P)$-atropisomer populations, but rather of a limited rotation leading to two hydrogen-bonded sub-populations within the $(M)$-atropisomer space. 

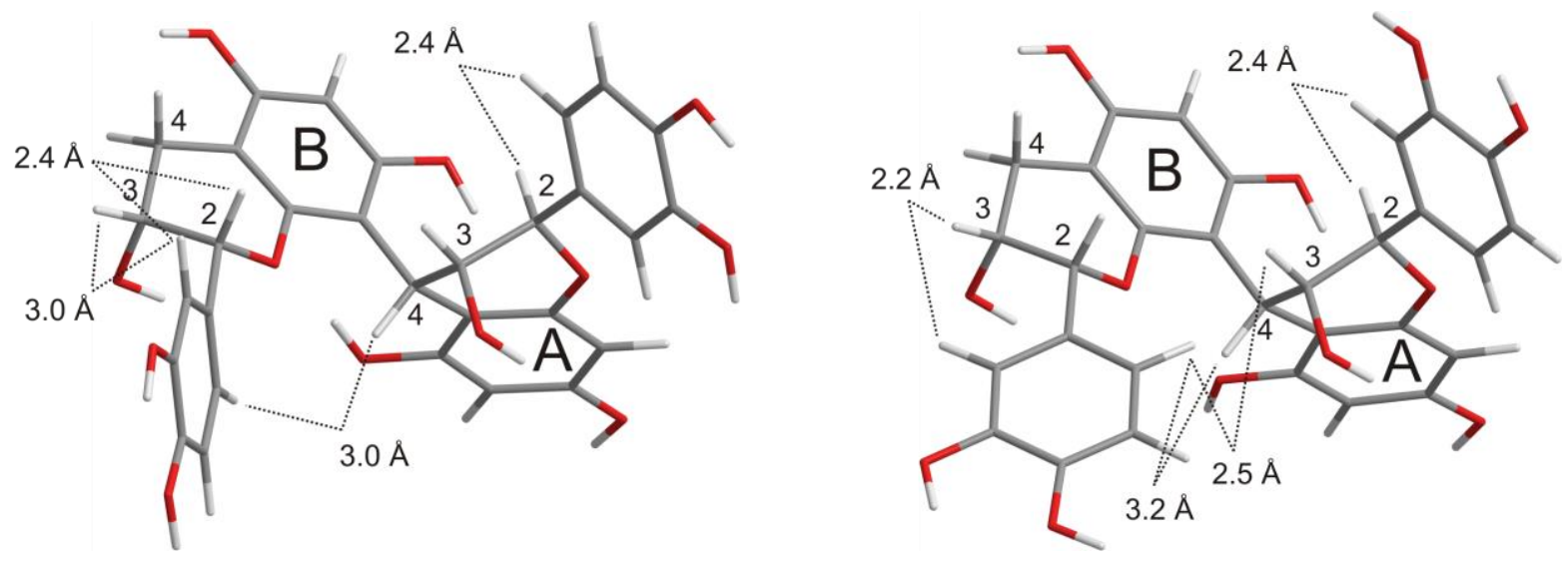

Figure 9. The lowest-energy conformation of $\mathbf{3}$ (left) and the third-lowest conformation (right) at the M05$2 x / 6-31 G * *$-level of theory (Table 2). The energy difference of $\Delta G=0.78 \mathrm{kcal} / \mathrm{mol}$ corresponded well to the experimental frozen conformer ratio of 5:1 (Fig. 4). Distance histograms from MD-simulation at $258 \mathrm{~K}\left(-15^{\circ} \mathrm{C}\right)$ were consistent with rOe experiments (strong enhancement for distances less than $3 \AA$ ) (Fig. 7).

Next, we investigated compound 4 whose experimental NMR data and nO-enhancements described above indicated $(M)$-atrop conformation for both inter-flavanol linkages. No significant half-chair interconversion for ring $A, B$, or $C$ was observed. Like in $\mathbf{2}$ and in 3, inter-flavanol bond rotation was restricted to the $(M)$-atrop space for both $A-B$ and B-C ring linkages in 4 (Fig. 10, top). However, two distinct conformational families in the $(M)$-atrop space around $-81^{\circ}$ (major) and $-60^{\circ}$ (minor) were observed for each of the two inter-flavanol linkages (Fig. 10, center). When the MD-trajectory was filtered with angular limits for the A-B-linkage $\left(-65^{\circ}<A-B<-55^{\circ}\right)$, the other linkage, $B-C$, only existed in the major conformation (Fig. 10, bottom). Analogously, when the data was filtered with angular limits for the B-C-linkage, the A-B-linkage was only observed in the major conformation as well. This implied that change of inter-flavanol linkage conformation was exclusive to one such linkage at a time and that out of $2 \times 2=4$ possible conformations only three were accessible. This was consistent with the three sets of NMR signals at low temperature as described above.

A total of seven conformations within $5 \mathrm{kcal} / \mathrm{mol}$ of the global minimum were identified for 4 with relative energies of 0.00 (I), +0.25 (II), +1.22 (III), +1.76 (IV), +2.19 (V), +2.22 (VI), and $+2.63 \mathrm{kcal} / \mathrm{mol}$ (VII) (Table 2 and Suppl. Material). The two lowest energy conformations were of the same dihedral angle value for both interflavanol linkages and only differed in the rotation of the catechol in ring A. They accounted for $\sim 88 \%$ of all structures. In the third conformation $(+1.22 \mathrm{kcal} / \mathrm{mol})$, the inter-flavanol linkage $A-B$, defined by $C 3^{A} C 4^{A} C 8^{B} C{ }^{B}$, had changed by about $20^{\circ}$ (from $-80.3^{\circ}$ to $-59.6^{\circ}$ ) and in the fourth conformation $(+1.76 \mathrm{kcal} / \mathrm{mol}$ ), the linkage $\mathrm{B}-\mathrm{C}$, defined by $\mathrm{C} 3^{\mathrm{B}} \mathrm{C} 4^{\mathrm{B}} \mathrm{C} 8^{\mathrm{C}} \mathrm{C} 9^{\mathrm{C}}$, had changed by about $20^{\circ}$ (from $-81.2^{\circ}$ to $-63.7^{\circ}$ ) (Fig. 11 , top). Proximity of Lewis basic oxygens and $\mathrm{OH}$-groups resulted in multiple hydrogen bonds. Like in $\mathbf{2}$ and $\mathbf{3}$, the limited rotation about the inter-flavanol linkage made intra-molecular $\mathrm{H}$-bonds possible.

Specifically, upon rotation of the A-B-linkage in (III), one additional $\mathrm{H}$-bond between the catechol $\mathrm{OH}$ group on $\mathrm{C} 3^{\mathrm{B}}$ and the $\mathrm{OH}$-group on $\mathrm{C} 3^{\mathrm{A}}$ was observed. However, the additional $\mathrm{H}$-bond only partially offset the energy expense associated with rotation of the A-B-linkage. Analogously, rotation of the B-C-linkage in conformation (IV) reduced the distance between the catechol $\mathrm{OH}$-group on $\mathrm{C}^{\prime}{ }^{\mathrm{C}}$ and the $\mathrm{OH}$-group on $\mathrm{C}^{\mathrm{B}}$. In none of the structures identified by us did the half-chair conformation deviate from ${ }^{2} \mathrm{H}_{3}$. All half-chairs were stabilized by $\mathrm{H}$-bonds between the respective $\mathrm{OH}$-group on $\mathrm{C} 3$ and the endocyclic oxygen. The lowest four 
structures were calculated at a theoretical abundance of 87.4:6.7:2.7 in good agreement with the 16:2:1 ratio determined by NMR.
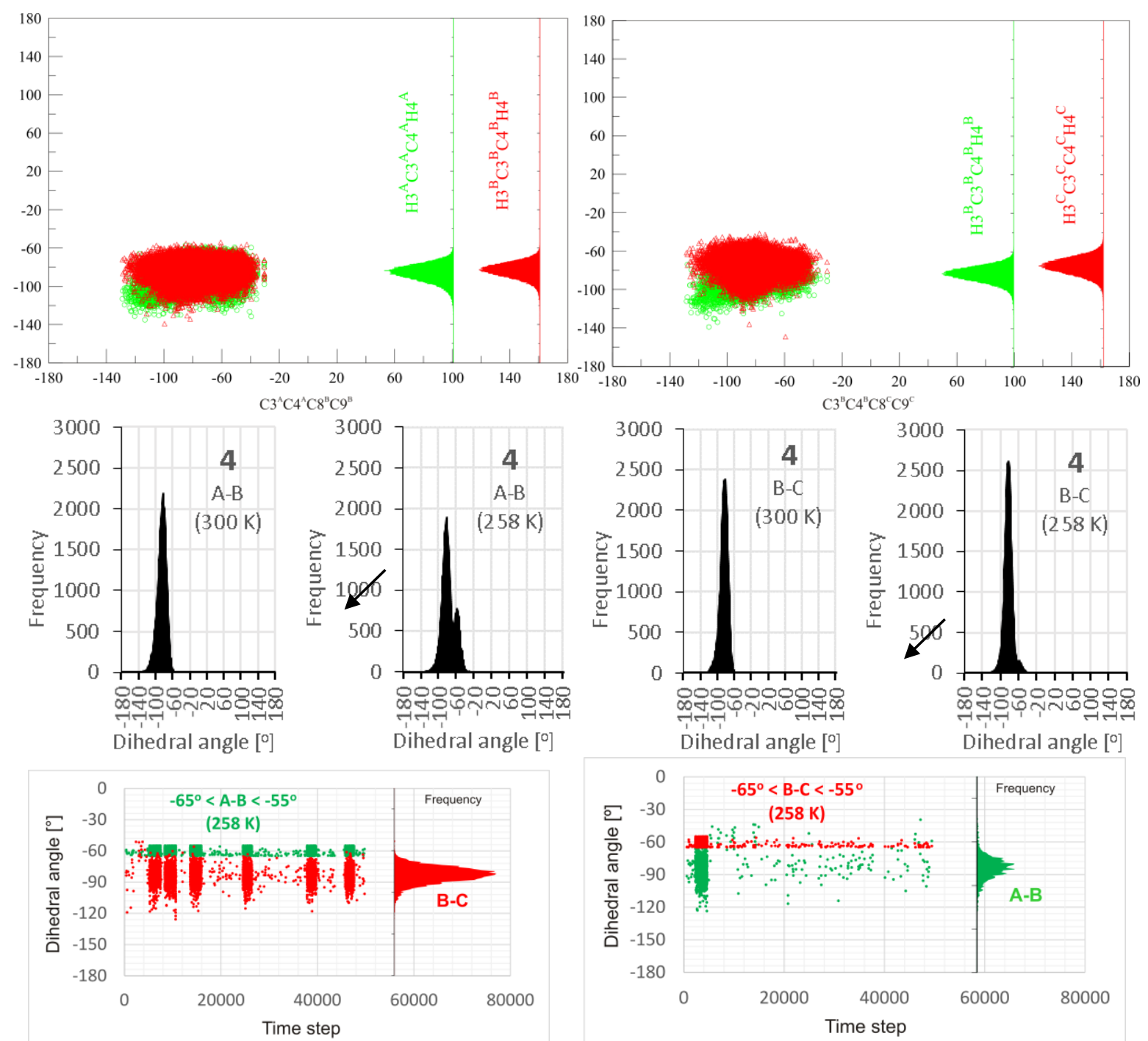

Figure 10. Top: Ramachandran plot and 2D-histogram projections for two diagnostic dihedral angles describing the half-chair in ring $A$ (green, o) and $B$ (red, $\Delta$ ) (left) and ring $B$ (green, o) and $C$ (red, $\Delta$ ) (right) versus the inter-flavanol dihedral angles $C 3^{A} C 4^{A} C 8^{B} C 9^{B}$ and $C 3^{B} C 4^{B} C 8^{C} C 9^{C}$ between the flavanol units in 4 at $258 \mathrm{~K}$, respectively. Center: MD-histograms of inter-flavanol linkages at $300 \mathrm{~K}$ and $258 \mathrm{~K}$. Bottom: Filtered MDhistograms of inter-flavanol linkages with angular limits on the respective inter-flavanol linkage.

Proton-proton distance analysis supported the experimentally observed nO-enhancements (Fig. 11, bottom). Despite higher molecular mass and greater structural complexity of $\mathbf{4}$, the catechol rings displayed free rotation in all three epicatechin units. Populations with significant contributions of inter-proton distances of less than $3 \AA$ were present for $\mathrm{H}^{\mathrm{A}}-\mathrm{H} 2^{\prime} \mathrm{A} / \mathrm{H} 6^{\prime} \mathrm{A}$, for $\mathrm{H} 3^{\mathrm{B}}-\mathrm{H} 2^{\prime} \mathrm{B} / \mathrm{H} 6^{\prime} \mathrm{B}$, and for $\mathrm{H}^{\mathrm{C}}-\mathrm{H} 2^{\prime} \mathrm{C} / \mathrm{H} 6^{\prime C}$ (Fig. 11, bottom). In addition, a small percentage of conformations in the $\mathrm{MD}$-trajectory resulted in $\mathrm{H} 3^{\mathrm{B}}-\mathrm{H} 2^{\prime} \mathrm{C} / \mathrm{H} 6^{\prime} \mathrm{C}$ distances close to $3 \AA$, which provided the structural rationale for weak nO-enhancements at $\mathrm{H} 2^{\prime} \mathrm{C} / \mathrm{H} 6^{\prime} \mathrm{C}$ (Fig. 5 inset) rather than dipolar through-space coupling to $\mathrm{H} 3^{\mathrm{A}}$. 

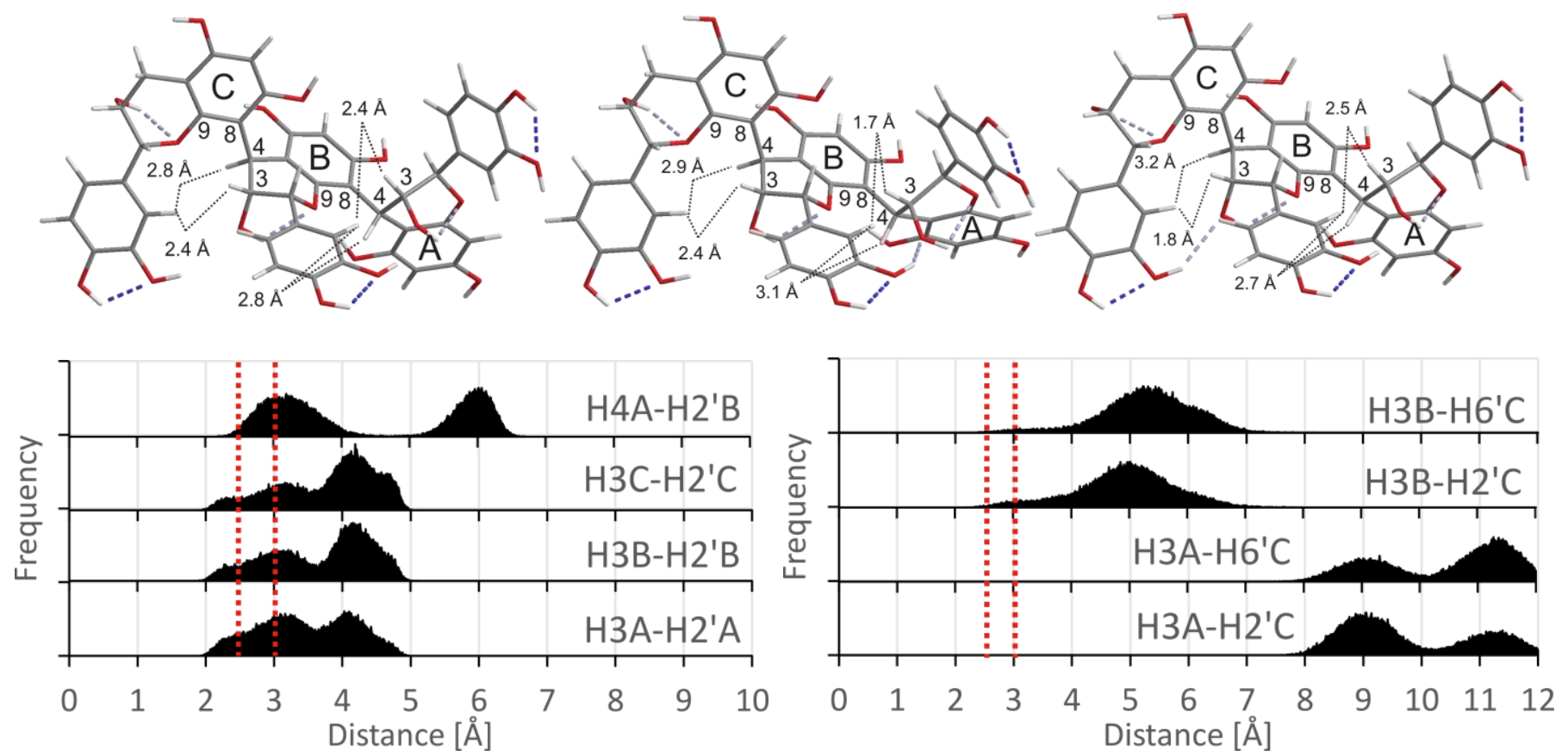

Figure 11. The lowest-energy conformations of 4. Top left: conformation (I) with dihedral angle A-B/B-C at $80.3^{\circ} /-81.2^{\circ}$; top center: conformation (III) at $-59.6^{\circ} /-81.1^{\circ}$; top, right: conformation (IV) at $-82.4^{\circ} /-63.7^{\circ}$ at the M05-2x/6-31G**-level of theory (Table 2). The energy difference of $\Delta G=+1.22 \mathrm{kcal} / \mathrm{mol}$ and $\Delta \mathrm{G}=+1.76$ $\mathrm{kcal} / \mathrm{mol}$ corresponded well to the experimental frozen conformer ratio of $\sim 16: 2: 1$. Bottom: Selected ${ }^{1} \mathrm{H}-{ }^{1} \mathrm{H}-$ distance histograms from MD-simulation of 4 at $258 \mathrm{~K}\left(-15^{\circ} \mathrm{C}\right)$.

\section{Conclusions}

The $(M)$-atropconformation dominated all inter-flavanol linkages in procyanidin $\mathrm{B} 1$, B2, and $\mathrm{C} 1$. No credible evidence for $(M) \rightarrow(P)$ rotation at estimated barriers of 30-35 kcal/mol was collected either experimentally or computationally. Rather, minor conformational isomers present in the NMR spectra at $-15{ }^{\circ} \mathrm{C}$ were identified as half-chair conformers (B1) and rotamer sub-families of the (M)-atropspace (B2 and C1). Nevertheless, the results of this research do not contradict any previously reported structural information about these three procyanidins in solution, such as circular dichroism studies. On the other hand, the results in solution from our study contrast in some cases with structural details in the solid state reported by others where apparently atroprotamers with opposite inter-flavanol helicity are accessible. The energetic reasons for such conformational changes reported in the literature are not clear and must be a direct consequence of crystal packing forces and sterics or, as in the case of protein-bound structures reported by others, a consequence of specific interactions within the protein binding pocket. Future rigorous thermodynamic studies of polyphenolprotein binding will be important to find a rationale for these observations. 


\section{Experimental Section}

\section{NMR Analysis}

NMR samples (Procyanidin B1, B2, C1: Sigma-Aldrich) were dissolved into methanol- $d_{4}$ (Cambridge Isotope Company, Massachusetts, USA) in high-precision NMR glass tubes (5mm OD) and spectra were recorded at rt or at $-15^{\circ} \mathrm{C}$ on a JEOL ECA-600MHz instrument with a dual-channel normal-geometry probe. All samples were shimmed at $r \mathrm{t}$ with spinning initially. Cooling was done with boiloff from liquid nitrogen ( $30 \mathrm{~L}$ Dewar). To conserve coolant, all sample at low temperature were analyzed without spinning. Shimming was adjusted manually at progressively lower temperatures to ascertain optimal line shape and resolution.

${ }^{1} \mathrm{H}$-Spectra: Collected with 32 scans and $16 \mathrm{k}$ data points, zero-filled to $64 \mathrm{k}$, prior to Fourier transformation. All ${ }^{13} \mathrm{C}$-chemical shifts were determined from indirect-detect experiments (HMQC). ${ }^{1} \mathrm{H}-{ }^{1} \mathrm{H}$-COSY spectra: Collected with 4 scans and 256 data points in the F1-dimension for a total of 1024 scans. ${ }^{1} \mathrm{H}_{-}{ }^{13} \mathrm{C}-\mathrm{HMQC}$ spectra: Collected with 32 scans and 256 data points in the F1-dimension for a total of 8192 scans. The F2-data was zero-filled to $2 \mathrm{k}$ and the F1-data was zero-filled to $1 \mathrm{k}$.

\section{NMR-Simulations}

${ }^{1} \mathrm{H}-\mathrm{NMR}$-Simulations were carried out with the NMRSim 6.0 module included in the TopSpin 3.5 pl7 software package (Bruker). For a given spin system, the module solves the Liouville equation, which describes the timedependent development of spin density during a given NMR pulse sequence. The spin systems were defined by chemical shifts, estimated $\mathrm{T}_{1}$-relaxation times (typically 0.3-0.4 s for aliphatic protons). Proton-proton coupling constants were adjusted iteratively to resemble the experimental spectrum.

\section{Molecular modeling}

The lowest conformer for molecular dynamic simulations was obtained from an exhaustive dihedral search using Spartan 14. Molecular dynamic simulations were performed using Amber $14,{ }^{43}$ with the GAFF force field. ${ }^{38-42}$ The structure was first minimized for 2000 cycles and then heated from $0 \mathrm{~K}$ to $300 \mathrm{~K}$ in $500 \mathrm{ps.} \mathrm{The}$ structure was then cooled from $300 \mathrm{~K}$ to $258 \mathrm{~K}$ in $500 \mathrm{ps}$. The MD simulation trajectories were 500 ns in length at a constant pressure using isotropic position scaling with sampling of the molecular coordinates every 1 ps. Long-range electrostatic interactions were treated using the particle mesh Ewald summation over $8 \AA$. Bonds containing hydrogen were constrained to their equilibrium lengths using the SHAKE algorithm. The explicit methanol solvent model was used to solvate the polyphenol with periodic boundary conditions giving a cubic box extending $10 \AA$ from each side of the molecule (total number of water molecules in box: 1b: 308, 2: 395, 3: 399, 4: 574. Trajectory analyses were carried out with VMD (Visual Molecular Dynamics). ${ }^{44}$ The trajectories of specific dihedral angles were then extracted and the data plotted as histograms. For structures in which multiple dihedral angles were investigated, each angle's total MD-trajectory was analyzed in form of a histogram to establish the conformational space.

\section{Atomic Charge Generation}

In the absence of preexisting atomic charges, they were derived using the two-stage RESP fit protocol, as established by Cornell et al. ${ }^{45}$ After an initial RESP fit based on Gaussian esp calculations (using the undocumented iop(6/33=2) option and pop=chelpg) and the espgen and respgen utilities of AmberTools16, a $50 \mathrm{~ns}$ MD simulation was run with the initial atomic charges. ${ }^{43}$ Then, 100 representative geometries were extracted from the MD trajectory and optimized at the HF/6-31G* level of theory, followed by a second RESP 
fit as described above which was averaged across all 100 conformers to give final values for the atomic charges.

\section{Quantum Mechanical Calculations}

Computations were performed using the Gaussian09 software package. ${ }^{46}$ Geometries were optimized at the $\mathrm{HF} / 6-31 \mathrm{G} *$ level and then the M05-2X/6-31G* level of theory using tight optimization criteria on ultrafine integration grid and used implicit PCM solvent correction for methanol. The M05-2X Minnesota functional was chosen for this study, as it was found by Csonka et al. and others to give better energetics than the commonly used Becke three-parameter Lee-Yang-Parr (B3LYP) functional, provided a higher density DFT grid was used. ${ }^{47-49}$ Additionally, Bally et al. found that reoptimization of geometry optimizations performed using the 631G* basis set with larger basis sets generally changed calculated coupling constants very little (rms change below $0.15 \mathrm{~Hz}$ ) and if the 'mixed' option is invoked, geometry reoptimization was found to have even less of an effect. ${ }^{34}$ The inclusion of diffuse functions (+) did not give notably better results, but increased time requirement more than 3-fold. Thus, 6-31G* was chosen as the basis set for the current study as a good compromise between accuracy and computational expense. In their study, Bally et al. also found no improvement upon adding implicit solvent model, however as this might not be the case with methanol and polyphenols, implicit PCM solvent correction was included. ${ }^{34}$ Fermi contact value calculations were performed using GIAO-NMR calculations (FConly, mixed) at the B3LYP/6-311G** $(d, p)[u+1 s]$ level of theory and implicit PCM solvent correction for methanol. The use of 'FCOnly' calculates only the Fermi contact term, saving significant computation time over the 'spinspin' option. As others have found, this is often the preferred option because the spin-orbit terms are negligible or cancel out for ${ }^{3} \mathrm{~J}_{\mathrm{CH}}$, thus leaving the Fermi contact term as the only relevant contribution. ${ }^{34,50} \mathrm{~A}$ correction factor of 0.92 was used for all ${ }^{3} \mathrm{~J}_{\mathrm{H}-\mathrm{H}}$ as recommended by Bally et al. ${ }^{34}$

\section{Acknowledgements}

The authors thank the Department of Chemistry for funding and Candice Cortney and Julie Pedraza for logistic support. Computational details were discussed with Dr. Sven Hackbusch. This work was made possible through a grant from the National Science Foundation (NSF-MRI-0722654). Mention of trade names or commercial products in this publication is solely for the purpose of providing specific information and does not imply recommendation or endorsement by the U.S. Department of Agriculture.

\section{Supplementary Material}

Additional NMR spectra (VT-1 ${ }^{1},{ }^{13} \mathrm{C}$-chemical shifts, ${ }^{1} \mathrm{H}-{ }^{1} \mathrm{H}-\mathrm{COSY},{ }^{1} \mathrm{H}-{ }^{13} \mathrm{C}-\mathrm{HMQC},{ }^{1} \mathrm{H}-{ }^{13} \mathrm{C}-\mathrm{HMBC}, 1 \mathrm{~d}$-pfg-TOCSY, and 1d-pfg-ROESY for all compounds), J-HMBC data for 1b, Haasnoot-deLeuw-Altona equations, MDhistograms (dihedral angles and inter-proton distances), and Cartesian coordinates of the minimized structures of all compounds are available online. 


\section{References}

1. Matkowski, A.; Jamiolkowska-Kozlowska, W.; Nawrot, I. Curr. Med. Chem. 2013, 20, 984-1004. http://dx.doi.org/10.2174/092986713805288888

2. Kirar, V.; Verma, M.; Brar, S. K.; Misra, K. In Polyphenols; Sun. J., Ed.; Nova Science Publishers, Inc.: Hauppauge, N. Y., 2013; p 461.

3. Castaneda-Ovando, A.; Pacheco-Hernandez, M. d. L.; Paez-Hernandez, M. E.; Rodriguez, J. A.; Galan-Vidal, C. A. Food Chem. 2009, 113, 859-871.

https://doi.org/10.1016/j.foodchem.2008.09.001

4. Li, X.; Ma, H.; Huang, H.; Li, D.; Yao, S. Nat. Prod. Res. 2013, 27, 456-469.

http://dx.doi.org/10.1080/14786419.2012.706299

5. Marienhagen, J.; Bott, M. J. Biotechnol. 2013, 163, 166-178.

https://doi.org/10.1016/j.jbiotec.2012.06.001

6. Thompson, R. S.; Jacques, D.; Haslam, E.; Tanner, R. J. N. J. Chem. Soc., Perkin Trans. 1 1972, $1387-1399$. http://dx.doi.org/10.1039/P19720001387

7. Weinges, K.; Goeritz, K.; Nader, K. Justus Liebigs Ann. Chem. 1968, 715, 164-171. http://dx.doi.org/10.1002/jlac.19687150118

8. Weinges, K.; Kaltenhauser, W.; Marx, H. D.; Nader, E.; Nader, F.; Perner, J.; Seiler, D. Justus Liebigs Ann. Chem. 1968, 711, 184-204.

http://dx.doi.org/10.1002/jlac.19687110123

9. Jacques, D.; Opie, C. T.; Porter, L. J.; Haslam, E. J. Chem. Soc., Perkin Trans. 1 1977, 1637-1643. http://dx.doi.org/10.1039/P19770001637

10. Platt, R. V.; Opie, C. T.; Haslam, E. Phytochemistry 1984, 23, 2211-2217. http://dx.doi.org/10.1016/S0031-9422(00)80522-1.

11. Fronczek, F. R.; Gannuch, G.; Mattice, W. L.; Tobiason, F. L.; Broeker, J. L.; Hemingway, R. W. J. Chem. Soc., Perkin Trans. 2 1984, 1611-1616.

http://dx.doi.org/10.1039/P29840001611

12. Fronczek, F. R.; Hemingway, R. W.; McGraw, G. W.; Steynberg, J. P.; Helfer, C. A.; Mattice, W. L. Biopolymers 1993, 33, 275-282.

http://dx.doi.org/10.1002/bip.360330209.

13. Hurlburt, B. K.; Offermann, L. R.; McBride, J. K.; Majorek, K. A.; Maleki, S. J.; Chruszcz, M. J. Biol. Chem. 2013, 288, 36890-36901.

http://dx.doi.org/10.1074/jbc.M113.517797.

14. Tsutsumi, H.; Kinoshita, Y.; Sato, T.; Ishizu, T. Chem Pharm. Bull. 2011, 59, 1008-1015. http://dx.doi.org/10.1248/cpb.59.1008

15. Weinges, K.; Schick, H.; Rominger, F. Tetrahedron 2001, 57, 2327-2330.

http://dx.doi.org/10.1016/S0040-4020(01)00099-0.

16. Ishizu, T.; Tsutsumi, H.; Sato, T. Chem. Pharm. Bull. 2016, 64, 676-686.

http://dx.doi.org/10.1248/cpb.c16-00131.

17. Li, C.; Li, M.; Chen, P.; Narayan, S.; Matschinsky, F. M.; Bennett, M. J.; Stanley, C. A.; Smith, T. J. J. Biol. Chem. 2011, 286, 34164-34174.

http://dx.doi.org/10.1074/jbc.M111.268599.

18. Slade, D.; Ferreira, D.; Marais, J. P. J. Phytochemistry 2005, 66, 2177-2215.

http://dx.doi.org/https://doi.org/10.1016/j.phytochem.2005.02.002. 
19. Ferreira, D.; Marais, J. P. J.; Slade, D. Phytochemistry 2005, 66, 2216-2237. http://dx.doi.org/https://doi.org/10.1016/j.phytochem.2005.01.014.

20. Gutowsky, H. S.; McCall, D. W.; Slichter, C. P. Phys. Rev. 1951, 84, 589-590. https://doi.org/10.1103/PhysRev.84.589.2

21. Karplus, M. J. Am. Chem. Soc. 1963, 85, 2870-2871. http://dx.doi.org/10.1021/ja00901a059

22. Karplus, M.; Anderson, D. H.; Farrar, T. C.; Gutowsky, H. S. J. Chem. Phys. 1957, 27, 597-598. https://doi.org/10.1063/1.1743784

23. Coxon, B. Adv. Carbohydr. Chem. Biochem. 2009, 62, 17-82. http://dx.doi.org/10.1016/s0065-2318(09)00003-1.

24. Franck, U.; Neszmelyi, A.; Wagner, H. ACH - Models Chem. 1999, 136, 511-517.

25. Hatano, T.; Hemingway, R. W. J. Chem. Soc., Perkin Trans. 2 1997, 1035-1043. http://dx.doi.org/10.1039/A605592C

26. Schmidt, C. A.; Murillo, R.; Heinzmann, B.; Laufer, S.; Wray, V.; Merfort, I. J. Nat. Prod. 2011, 74, 14271436. http://dx.doi.org/10.1021/np200158g.

27. Tarascou, I.; Barathieu, K.; Simon, C.; Ducasse, M.-A.; Andre, Y.; Fouquet, E.; Dufourc, E. J.; de Freitas, V.; Laguerre, M.; Pianet, I. Magn. Reson. Chem. 2006, 44, 868-880.

http://dx.doi.org/10.1002/mrc.1867.

28. Hemingway, R. W.; Tobiason, F. L.; McGraw, G. W.; Steynberg, J. P. Magn. Reson. Chem. 1996, 34, 424433.

http://dx.doi.org/10.1002/(SICI)1097-458X(199606)34:6<424::AID-OMR902>3.0.CO;2-9.

29. Killday, K. B.; Davey, M. H.; Glinski, J. A.; Duan, P.; Veluri, R.; Proni, G.; Daugherty, F. J.; Tempesta, M. S. J. Nat. Prod. 2011, 74, 1833-1841.

http://dx.doi.org/10.1021/np1007944.

30. Khan, M. L.; Haslam, E.; Williamson, M. P. Magn. Reson. Chem. 1997, 35, 854-858. http://dx.doi.org/10.1002/(SICl)1097-458X(199712)35:12<854::AID-OMR184>3.0.CO;2-N

31. Shoji, T.; Mutsuga, M.; Nakamura, T.; Kanda, T.; Akiyama, H.; Goda, Y. J. Agric. Food Chem. 2003, 51, 38063813.

http://dx.doi.org/10.1021/jf0300184.

32. Esatbeyoglu, T.; Jaschok-Kentner, B.; Wray, V.; Winterhalter, P. J. Agric. Food Chem. 2011, 59, 62-69. http://dx.doi.org/10.1021/if1032334.

33. Franz, A. H.; Serebnitskaya, I.; Gudial, G.; Wallis, C. Arkivoc 2014, (v), 94-122. http://dx.doi.org/10.3998/ark.5550190.p008.583.

34. Bally, T.; Rablen, P. R. J. Org. Chem. 2011, 76, 4818-4830. http://dx.doi.org/10.1021/jo200513q.

35. Haasnoot, C. A. G.; De Leeuw, F. A. A. M.; Altona, C. Tetrahedron 1980, 36, 2783-2792. http://dx.doi.org/10.1016/0040-4020(80)80155-4.

36. DeAngelis, G. G.; Wildman, W. C. Tetrahedron 1969, 25, 5099-5112. http://dx.doi.org/10.1016/S0040-4020(01)83255-5.

37. Gaffield, W.; Foo, L. Y.; Porter, L. J. J. Chem. Res., Synop. 1989, 144-145.

38. Bras, N. F.; Goncalves, R.; Fernandes, P. A.; Mateus, N.; Ramos, M. J.; de F. V. Biochemistry 2010, 49, 50975108.

http://dx.doi.org/10.1021/bi100410q 
39. Ge, H.; Liu, J.; Zhao, W.; Wang, Y.; He, Q.; Wu, R.; Li, D.; Xu, J. Org. Biomol. Chem. 2014, 12, 4941-4951. http://dx.doi.org/10.1039/C40B00589A.

40. Kumar, P.; Choonara, Y. E.; Pillay, V. Molecules 2015, 20, 135-168. http://dx.doi.org/10.3390/molecules20010135.

41. Li, X.; Zhang, W.; Qiao, X.; Xu, X. Bioorg. Med. Chem. 2007, 15, 220-226. http://dx.doi.org/10.1016/j.bmc.2006.09.074.

42. Manivannan, A.; Soundararajan, P.; Park, Y. G.; Sakkiah, S.; Jeong, B. R. J. Chem. 2015, 1-13. http://dx.doi.org/10.1155/2015/434256.

43. Case, D. A. B., R.M; Botello-Smith, W.; Cerutti, D.S.; Cheatham III, T.E.; Darden, T.A.; Duke, R.E.; Giese, T.J.; Gohlke, H.; Goetz, A.W.; Homeyer, N.; Izadi, S.; Janowski, P.; Kaus, J.; Kovalenko, A.; Lee, T.S.; LeGrand, S.; Li, P.; Lin, C.; Luchko, T.; Luo, R.; Madej, B.; Mermelstein, D.; Merz, K.M.; Monard, G.; Nguyen, H.; Nguyen, H.T.; Omelyan, I.; Onufriev, A.; Roe, D.R.; Roitberg, A.; Sagui, C.; Simmerling, C.L.; Swails, J.; Walker, R.C.; Wang, J.; Wolf, R.M.; Wu, X.; Xiao, L.; York D.M. and Kollman P.A., AMBER 2016, University of California, San Francisco, 2016

44. Humphrey, W.; Dalke, A.; Schulten, K. J. Mol. Graph. 1996, 14, 33-38. http://dx.doi.org/10.1016/0263-7855(96)00018-5.

45. Cornell, W. D.; Cieplak, P.; Bayly, C. I.; Kollmann, P. A. J. Am. Chem. Soc. 1993, 115, 9620-9631. http://dx.doi.org/10.1021/ja00074a030.

46. Frisch, M. J.; Trucks, G. W.; Schlegel, H. B.; Scuseria, G. E.; Robb, M. A.; Cheeseman, J. R.; Scalmani, G.; Barone, V.; Mennucci, B.; Petersson, G. A.; Nakatsuji, H.; Caricato, M.; Li, X.; Hratchian, H. P.; Izmaylov, A. F.; Bloino, J.; Zheng, G.; Sonnenberg, J. L.; Hada, M.; Ehara, M.; Toyota, K.; Fukuda, R.; Hasegawa, J.; Ishida, M.; Nakajima, T.; Honda, Y.; Kitao, O.; Nakai, H.; Vreven, T.; Montgomery Jr., J. A.; Peralta, J. E.; Ogliaro, F.; Bearpark, M. J.; Heyd, J.; Brothers, E. N.; Kudin, K. N.; Staroverov, V. N.; Kobayashi, R.; Normand, J.; Raghavachari, K.; Rendell, A. P.; Burant, J. C.; Iyengar, S. S.; Tomasi, J.; Cossi, M.; Rega, N.; Millam, N. J.; Klene, M.; Knox, J. E.; Cross, J. B.; Bakken, V.; Adamo, C.; Jaramillo, J.; Gomperts, R.; Stratmann, R. E.; Yazyev, O.; Austin, A. J.; Cammi, R.; Pomelli, C.; Ochterski, J. W.; Martin, R. L.; Morokuma, K.; Zakrzewski, V. G.; Voth, G. A.; Salvador, P.; Dannenberg, J. J.; Dapprich, S.; Daniels, A. D.; Farkas, Ö.; Foresman, J. B.; Ortiz, J. V.; Cioslowski, J.; Fox, D. J., Gaussian 09, Gaussian, Inc., Wallingford, CT, USA, 2009

47. Csonka, G. I.; French, A. D.; Johnson, G. P.; Stortz, C. A. J. Chem. Theory Comput. 2009, 5, 679-692. http://dx.doi.org/10.1021/ct8004479.

48. Marianski, M.; Supady, A.; Ingram, T.; Schneider, M.; Baldauf, C. J. Chem. Theory Comput. 2016, 12, 61576168.

http://dx.doi.org/10.1021/acs.jctc.6b00876.

49. Zhao, Y.; Schultz, N. E.; Truhlar, D. G. J. Chem. Theory Comput. 2006, 2, 364-382. http://dx.doi.org/10.1021/ct0502763.

50. Bagno, A.; Rastrelli, F.; Saielli, G. J. Phys. Chem. A 2003, 107, 9964-9973. http://dx.doi.org/10.1021/jp0353284. 